\title{
Volcanic ballistic projectile deposition from a continuously erupting volcano: Yasur Volcano, Vanuatu
}

\author{
Rebecca H. Fitzgerald ${ }^{\star \alpha}$, Ben M. Kennedy ${ }^{\alpha}$, Christopher Gomez $^{\beta}$, Thomas M. Wilson ${ }^{\alpha}$, \\ Ben Simons $\gamma$, Graham S. Leonard ${ }^{\delta}$, Robin S. Matoza ${ }^{\epsilon}$, Arthur D. Jolly ${ }^{\delta}$, Esline Garaebiti $\zeta$ \\ ${ }^{\alpha}$ Department of Geological Sciences, University of Canterbury, Private Bag 4800, Christchurch 8140, New Zealand. \\ $\beta$ Graduate School of Maritime Sciences, Kobe University, 1-1, Rokkodai-cho, Nada-ku, Kobe, 657-8501, Japan. \\ $\gamma$ School of Environment, University of Auckland, Private Bag 92019, Auckland 1142, New Zealand.

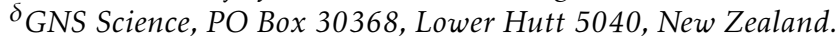 \\ ${ }^{\epsilon}$ Department of Earth Science and Earth Research Institute, Webb Hall MC 9630, \\ University of California Santa Barbara, Santa Barbara, CA 93106, USA.

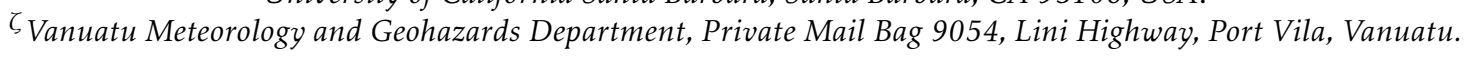

\begin{abstract}
Volcanic Ballistic Projectiles (VBPs) are the main hazard to life and infrastructure from Strombolian eruptions. This eruption style is a tourist drawcard, exposing people to VBP hazard. Most of the research on VBPs to date has been focussed on understanding how they form and their trajectory. However, little focus has been placed on how they are spatially distributed within VBP fields or the inclusion of these data into hazard and risk assessments. In this study, we used a drone to image the east and south flanks of Yasur Volcano, Vanuatu, and cameras, infrasound, and seismicity to record explosions from 28 July to 2 August and 17 to 19 October 2016. We present the mapped spatial distribution of VBPs from the two trips, assessing how the VBP field changes with distance and direction from the vent, and how eruption dynamics influence these changes. We found that the VBP spatial density and median diameter decrease with distance from the crater. Spatial density was also found to vary with direction around the crater, with higher spatial densities found in the S-SSE than other directions. Combined with observations of explosions, we attribute the changes in spatial density to explosion directionality. Our evidence for directionality results in considerable variation in summit VBP hazard and is an important, but by no means the sole, consideration for VBP hazard and risk assessments.
\end{abstract}

Keywords: Volcanic ballistics; Ballistic distribution; UAV mapping; Yasur Volcano; Ballistic hazard assessment

\section{InTRODUCTION}

Erupting volcanoes are increasingly frequented by tourists [Erfurt-Cooper et al. 2015]. For example, Yasur volcano, on the SE of Tanna Island, Vanuatu, attracts $\sim 50$ tourists a day, who often spend two or more hours watching the frequent Strombolian explosions from the crater rim. Such proximity to the explosions exposes visitors and guides to multiple volcanic hazards, with Volcanic Ballistic Projectiles (VBPs) globally the most common cause of volcanic fatalities for tourists [Brown et al. 2017]. VBPs are fragments of molten lava or solid rock and can range from a few centimetres to tens of metres in diameter [Andronico et al. 2015; Bower and Woods 1996; Gurioli et al. 2013; Nairn and Self 1978; Taddeucci et al. 2017; Tsunematsu et al. 2016], can travel tens to hundreds of metres per second [Fudali and Melson 1971; Pioli et al. 2008; Taddeucci et al. 2012; Yamagishi and Feebrey 1994] and

${ }^{*}$ Corresponding author: bec.fitzgerald4@gmail.com up to $\sim 10 \mathrm{~km}$ from vent, although they are usually limited to within $5 \mathrm{~km}$ [Alatorre-Ibargüengoitia et al. 2012; Blong 1984; Gurioli et al. 2013; Kilgour et al. 2010; Minakami 1942]. Their often high impact and thermal energies make them a potentially lethal hazard [AlatorreIbargüengoitia et al. 2012; Baxter and Gresham 1997; Blong 1984; Tsunematsu et al. 2016; Wardman et al. 2012]. Three of the 367 globally recorded fatalities from VBP strike have occurred at Yasur [Brown et al. 2017]. VBPs are also capable of damaging exposed vehicles [Andronico et al. 2015; Global Volcanism Program 2001; Wardman et al. 2012], buildings [Booth 1979; Jenkins et al. 2014; Pistolesi et al. 2008; Williams et al. 2017; Williams et al. 2019], infrastructure [Andronico et al. 2015; Pistolesi et al. 2008; Wardman et al. 2012] and agriculture [Stern 2007; Wardman et al. 2012].

Risk reduction and mitigation measures (such as land use planning, exclusion zones, protective-wear, shelters, communication and education products) are 
key to reducing risk to visitors, though to be most effective they must be supported by robust hazard and risk assessment [Fitzgerald et al. 2017]. VBP hazard assessments determine the likelihood of VBP-producing eruptions and the likely impacted areas [AlatorreIbargüengoitia et al. 2012; Thouret et al. 2000]. VBP risk assessments go one step further and determine the likelihood of specific consequences occurring (e.g. fatalities, casualties, damage) due to the exposure to VBPs [Blong 1996]. Increasing tourism and other activities on active volcanic summit areas leads to greater exposure to the hazard, and there are increasing regulatory requirements and societal expectations to inform users about the risk to which they may be exposed [Deligne et al. 2018; Jolly et al. 2014]. These have driven the requirement to more accurately assess risk so that it may be evaluated and treated within a risk management framework. Yet, our understanding of VBP hazard is relatively limited. A lack of detailed mapping of how VBPs are distributed in space (VBP fields) during explosive eruptions is notable with only a few fully mapped VBP fields reported [e.g. Fitzgerald et al. 2014; Gurioli et al. 2013; Swanson et al. 2012]. The main reasons for this are fieldwork time constraints (mapping every individual VBP on foot is time-consuming), the high risk involved in mapping proximal vent areas especially during unrest or eruption phases, the resolution limitations of readily available remote sensing imagery, and the limited geological preservation of VBP fields due to cover from ash and lapilli and subsequent erosion. Instead, published VBP distribution maps often only show the maximum travel distance or extent of the field [Minakami 1942; Nairn and Self 1978; Robertson et al. 1998; Yamagishi and Feebrey 1994]. This does not give a complete understanding of the hazard and can lead to inaccurate estimations of risk, particularly without the knowledge of spatial density. Sufficiently high resolution aerial photos help get a wider understanding of field characteristics, making mapping the field possible and allowing for targeted field investigations to supplement and check the accuracy of photo mapped data, maintain detail and reduce uncertainty in identifying VBPs. As such, aerial photos have been used to map VBP fields [Breard et al. 2014; Fitzgerald et al. 2014; Kaneko et al. 2016]. Previously this has been accomplished using planes and helicopters. However, the use of these aircraft is expensive and can be a limitation for scientists with limited resources.

Drones, or remotely piloted aircraft, are a tool that can be used to assess geological hazards [Gomez and Purdie 2016] while reducing the risk to scientists. They offer particular capabilities that lend themselves to volcano observation and monitoring. This includes: (1) access to dangerous or hard to reach areas while keeping scientists at a safer distance from the hazard; (2) portability; (3) ability to produce higher resolution outputs compared with those taken by larger aircraft such as helicopters, by being able to get closer to fea- tures; and (4) relatively low cost. For example, drones have been used in volcanic research to thermally map a geothermal valley [Harvey et al. 2016], observe crater activities in active volcanoes [Jordan 2015; Patterson et al. 2005], map active lava flows and model future flow paths [Turner et al. 2017], determine the likely location of magma and dykes using aeromagnetic surveys [Kaneko et al. 2011], measure the gas composition [Shinohara 2013] and flux from a volcanic plume [McGonigle et al. 2008], 3D image a volcanic plume [Gomez and Kennedy 2018], and survey land changes after volcanic eruptions [Nakano et al. 2014]. Two MSc theses have assessed the methodology of using drones to map VBP fields [Gates 2018; Pitchika 2017], though to the best of our knowledge, no-one has utilised a drone to map VBP fields and assess VBP hazard.

In this paper we present the results of two field campaigns from 28 July to the 2 August and 17 to the 19 October 2016 to map the VBP field and understand the VBP hazard at Yasur. The study objectives were to: (1) use drones and photogrammetry to determine the distribution and varying spatial intensity of the hazard (both the number and size of VBPs) constrained between the two flights; and (2) evaluate explosion frequency and dynamics from video footage to understand how this influences the VBP hazard distribution at Yasur. The results presented here will add to the limited data available on VBP distributions from Strombolian eruptions, improve our knowledge of how VBP fields vary with distance and direction from vent and over time, and improve understanding on the causes of heterogeneity in hazard around a vent as well as within a field. The paper is structured into four main sections. We describe our methodology, followed by results which are subdivided into Spatial distribution containing mapping results and Eruption dynamics containing video and observation derived results. Then we discuss the relationship between VBP size and distance from vent, how spatial density changes with direction around the vents, differences between the two data sets, and finally, we describe the hazard/risk implications of our results.

\subsection{Eruptive history}

Yasur is a basaltic trachy-andesite scoria cone $361 \mathrm{~m}$ a.s.l. (at the summit; $169^{\circ} 26^{\prime} 43.06^{\prime \prime} \mathrm{E}$ $\left.19^{\circ} 31^{\prime} 36.74^{\prime \prime} \mathrm{S}\right)$, situated within the $>20$ ka Siwi caldera at the north-western edge of the Yenkahe resurgent dome [Battaglia et al. 2016; Brothelande et al. 2016; Gaudin et al. 2014; Merle et al. 2013; Métrich et al. 2011]. At its base, the cone is $1500 \mathrm{~m}$ in diameter, while the summit is irregular in height-highest in the west and south and decreasing in elevation towards the north and east. Present-day Yasur is composed of a $660 \mathrm{~m}$ diameter crater subdivided into two sub-craters with three main vent areas (A and B in the southern 
sub-crater, and $\mathrm{C}$ in the northern sub-crater) [Battaglia et al. 2016; Kremers et al. 2012; Meier et al. 2016; Nabyl et al. 1997; Oppenheimer et al. 2006; Spina et al. 2015, Figure 1]. It is evident that the positions of the vents migrate over time and the two southern vent areas (A and B) are alternately named by different authors. Drone footage from this study revealed a change in the number and position daily of vents in both the North and South craters. Thus, we have decided to adopt the Jolly et al. [2017] naming convention of simply North and South Crater.

Firth et al. [2014] identified 3 stages of eruption from tephra stratigraphy and literature review: pre-700 AD, a variable frequency and intensity eruptive episode; from $700 \mathrm{AD}$ to $1270 \mathrm{AD}$ a higher magnitude lower frequency episode; and from $1270 \mathrm{AD}$ to the present a persistently active low magnitude high frequency episode. This most recent eruptive stage has been predominantly Strombolian with intermittent Vulcanian activity [Bani and Lardy 2007; Firth et al. 2014; Nabyl et al. 1997]. Explosion frequency has been variable over the current high frequency stage. Meier et al. [2016] reported explosions several times a minute over a 15day period in 2008, while Marchetti et al. [2013] and Battaglia et al. [2016] reported a frequency of at least one explosion per minute (over 4 days in July - August 2008 and the entire year of 2008, respectively). Kremers et al. [2013] report similar results of explosion recurrence under one minute (from Vent Area A) over two weeks in August-September 2008. However, Vent Area $B$ frequency ranged from minutes to days and Vent Area $C$ had strong explosions every 10 minutes. Vent Area B explosion recurrence was reported to be on the minutes end of the range by Oppenheimer et al. [2006] with 13 explosions occurring over a 15-minute period in January 2005. Over a two-hour period in September 2011, Bani et al. [2013] recorded 200 explosions from Vent Area B using a thermal infrared thermometer. Infrasound recordings reported by Pichon [2005] showed 20-1300 explosions per day.

\section{Methodology}

VBP fields can cover large areas (e.g. $6 \mathrm{~km}^{2}$ in area recorded by Fitzgerald et al. [2014]), making them difficult to map in detail due to the time needed to record all pertinent information from each VBP (e.g. dimensions, lithology, crater formation, impact angle) and the sheer number of VBPs that are contained in the field [Fitzgerald et al. 2014]. Aerial photography and photogrammetry allow for mapping to be done remotely, in detail over the whole area and in a much shorter time frame. In our study, a DJI Phantom 3 drone was flown over the crater and flanks of Yasur Volcano, capturing 3,863 images and covering an area of $0.82 \mathrm{~km}^{2}$ from NE to $S$ (Figure 2) at heights above the ground up to $60 \mathrm{~m}$ with a 12-megapixel camera. Time and equipment re- strictions meant limiting flying to a $135^{\circ}$ swath of the volcano, with the NE-S area chosen due to it encompassing the viewing areas, track, and carpark. Eight orthophotographs and accompanying DEMs were created from these images using Structure from Motion (SfM) software (PhotoScan) in high enough resolution to map individual VBPs. Flights were flown on autopilot (using the Map Pilot application) with flight paths created on an iPad in the field. Using Map Pilot ensured that photos were taken with sufficient overlap for SfM to be used and that no areas were missed.

Geospatial data was collected using a Trimble R8 Real-Time Kinematic Global Navigation Satellite System (RTK GNSS), with a base station set up at the edge of the car park (Figure 2) and linked to the drone imagery through ground control points taken at ground targets visible in the aerial images.

Although RTK GNSS produces a typical location error in $\mathrm{X}, \mathrm{Y}<2-5 \mathrm{~cm}$ and $<10 \mathrm{~cm}$ in $\mathrm{Z}$ compared to single GNSS and GPS units, the SfM photogrammetric method relies on statistical approximation of the camera characteristics [Westoby et al. 2012] and on the resolution of the imagery [Gomez 2014]. Therefore, even with GNSS RTK tie points, error can spread in between the ground control points and precisely aligning the produced orthophotographs and DEMs from the two trips can be challenging once imported into the ArcGIS environment. To make visual comparisons between the two orthophoto datasets easier and rectify the misalignment, the orthophotos and DEM sets were stacked in the GIS software ENVI and exported as combined TIFFs. The stacks were then imported into ArcGIS where they were split into smaller areas (between 4 and 20 depending on the size of the area the original orthophoto covered) and georeferenced to each other. Splitting the layers resulted in more accurate georeferencing as it reduced the warping produced when the larger datasets were used.

As the area captured in the orthophotos was too large to map all VBPs in the available timeframe, twentythree $20 \times 20 \mathrm{~m}$ squares (an area of $400 \mathrm{~m}^{2}$ for each square) were visually mapped from the orthophotos from the July-August trip and thirty from the October trip (as the latter covered a larger area). The squares were positioned at $100 \mathrm{~m}$ increments and along transects $22.5^{\circ}$ apart radiating from a central point between the two craters (hereafter called the crater mid-point) to capture as much of the orthophoto area and variation in VBP distribution around the volcano as possible (Figure 2). A central point between the two craters was chosen as it was not possible to distinguish which VBP came from which vent. Spatial density contours were then applied to the mapped distributions using the spline tool in ArcGIS and best fit estimates. In addition to the location being recorded, VBP dimension (taken from the largest axis) and whether an impact crater has been produced and its dimensions was also noted. Identification of VBPs was based on mul- 

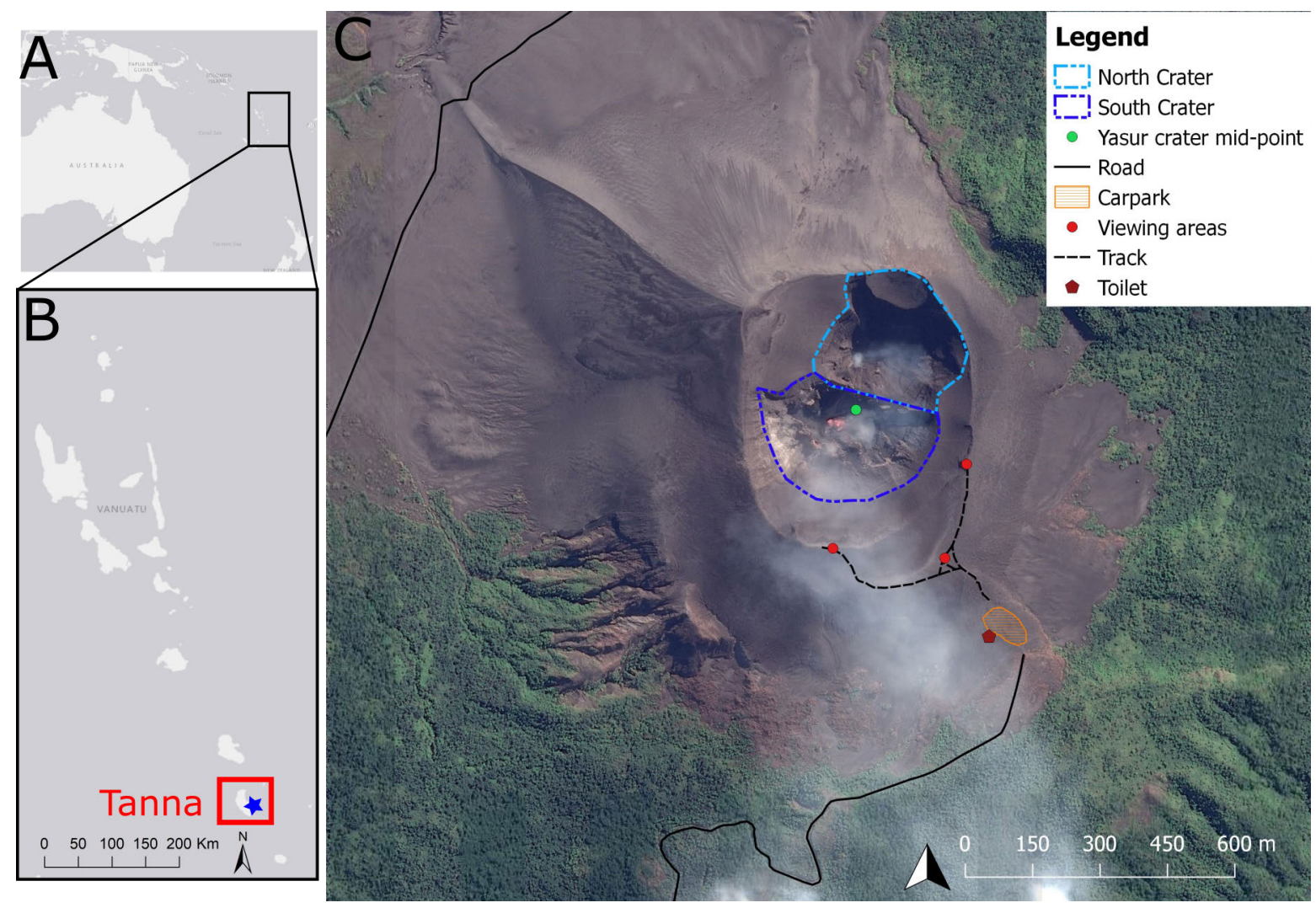

Figure 1: Location maps of Vanuatu in relation to Australia and New Zealand [A] and the island of Tanna [B] with a blue star indicating where Yasur is. Yasur Volcano (169 26' 43.06" E $19^{\circ} 31^{\prime}$ 36.74" S), the two sub-craters and the location of infrastructure are shown in [C]. Background image (C) 2019 Google.

tiple factors though not all were required for identification. Factors included (1) morphology (a small topographic increase caused by VBP sitting on the surface, distinct VBP rounding or angularity), (2) colour differences (darker or lighter clasts compared to the ground surface), (3) round depressions around or near a VBP indicating impact with the ground, and (4) disturbed material around a VBP indicating an impact. Figure 3 illustrates this process, showing mapping squares preand post-VBP identification. Comparison of the JulyAugust and October orthophotos helped to identify new VBPs that had landed post July-August data collection and also confirmed if something was a VBP (i.e. seeing it in a slightly different light or angle in a different orthophoto could help to confirm it was a VBP and not a lighter patch of ground or autobreccia from the old lava flows on the flanks). Unfortunately due to time constraints in the field, we could not ground-truth the mapping squares to assess for resolution and mapping error.

Along with the drone flights, three GoPro Hero $3+$ cameras with orthorectified lenses were set up around the crater rim to record eruption dynamics and frequency for 10 hours over 30 July to 1 August 2016 (Figure 2). Each camera could see into the crater though not to the vents as crater walls blocked these from view. When possible, we assessed the size and directionality of the explosions from the GoPro video footage. Multiple locations around the crater and concurrent filming from the cameras meant that directionality could be checked at another angle, reducing stereological effects. Directionality was classified (by sight) on the angle of the eruption jet in relation to landmarks around the crater (i.e. the jet was directed towards the viewing areas to the east and south). Explosions were sized based on the height that VBPs or a sustained tephra plume reached (small: a third of the way up the crater; moderate: between a third of the crater height and the crater rim; large: above the crater rim). An anemometer (Kestrel $5500 \mathrm{~L}$ ) was also installed at the southern viewing area (Figure 1C) to record wind speed and direction every 1 to 5 minutes over 29 July to 1 August. Additionally, systematic observational logs were collected for one hour each day from the seating/viewing area in the SSE from 5 September to 16 October 2016 in between the two imaging trips by B. Simons. This record provided the source crater that any bombs were coming from, which direction they were landing and if they landed outside the crater rim.

As part of concurrent studies [Iezzi et al. 2019; Jolly et al. 2017; Matoza et al. 2017], a temporary infrasound and seismic network was set up around the cone. Two stations from this network (YIB22 and YS01), located $\sim 700 \mathrm{~m}$ from the vent area, are used in this pa- 


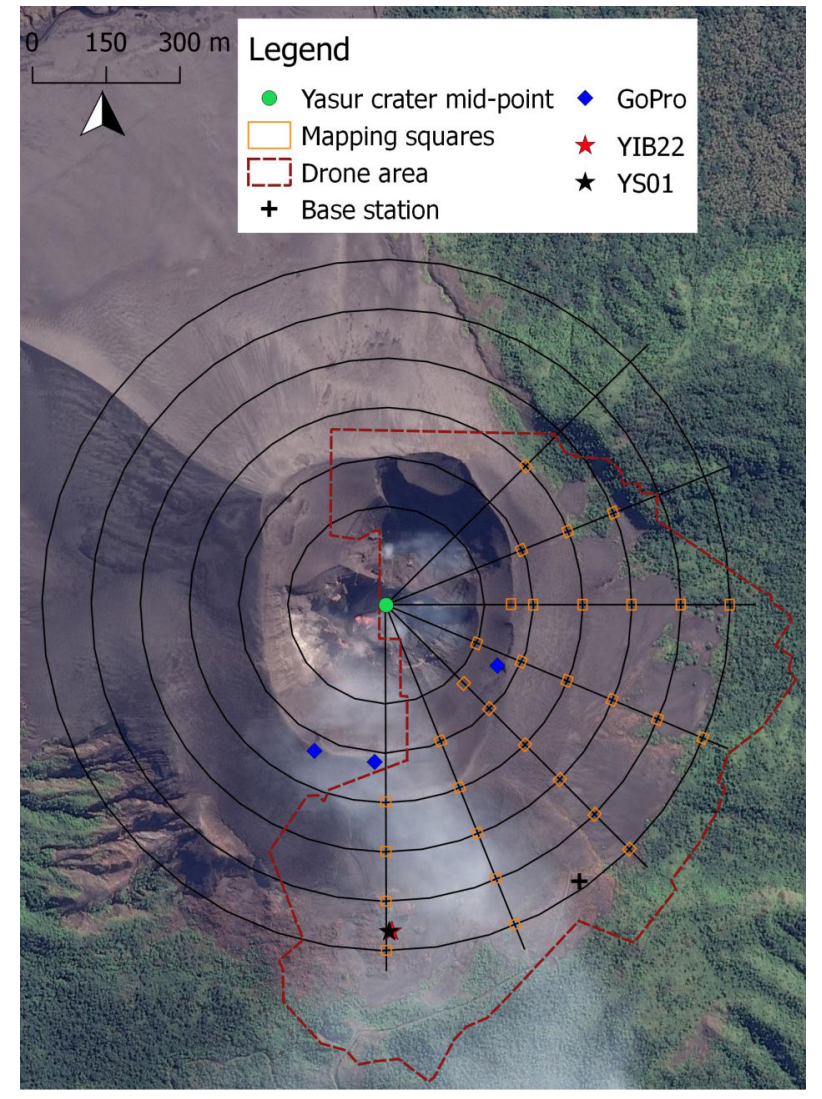

Figure 2: The crater mid-point, $100 \mathrm{~m}$ radii and transects used to create the mapping squares. Also shown is the area that the drone imaged, and locations of equipment used. Background image (c) 2019 Google.

per to support changes in eruptive activity observed in video footage from the same time period. These stations are also used to place the explosion events selected for analysis in this study in context with the continuous ongoing activity. As a proxy for event size, we use peak event amplitudes from unfiltered infrasound waveforms from YIB22 in a time-window from -5 to $+10 \mathrm{~s}$ around an automatic network-coincident STA/LTA trigger. The STA/LTA detection was performed with $0.1-50 \mathrm{~Hz}$ filtered data using an STA length of $0.5 \mathrm{~s}$, an LTA length of $40 \mathrm{~s}$, and a coincident STA/LTA threshold of 3 on at least 2 stations of a 3element array. Real-Time Infrasonic Amplitude (RIAM) and Real-Time Seismic Amplitude (RSAM) were also estimated as the 10-minute mean of absolute amplitude of 0.1-50 Hz filtered data [Endo and Murray 1991].

\section{Results AND ANALYsis}

This section is divided into two subsections: Spatial distribution, which reports results from the aerial mapping; and Eruption dynamics which conveys the results from the GoPro footage and visual observations.

\subsection{Spatial distribution}

We present two VBP distributions from Yasur volcano. The first is of VBPs deposited between 28 July and 19 October 2016 (hereafter referred to as the two-month distribution), by mapping VBPs that appear only in the October images and that are not present in the JulyAugust images. The second was the distribution of all observable VBPs in October, which includes the longerterm distribution of VBPs deposited potentially over months to years.

From the two-month distribution, 1,550 new VBPs were identified from 23 mapping squares (each square $400 \mathrm{~m}^{2}$ in area). VBP diameters ranged from $5 \mathrm{~cm}$ (the minimum size that could be distinguished) to 304 $\mathrm{cm}$ with a mean of $43 \mathrm{~cm}$. The number of VBPs per $\mathrm{m}^{2}$ drops rapidly as distance from the crater increases, from $182 \times 10^{-2} \mathrm{~m}^{-2}$ at $200 \mathrm{~m}$ from the crater midpoint (defined in section 2) to an average of $6.69 \times$ $10^{-2} \mathrm{~m}^{-2}$ at a distance of $400 \mathrm{~m}$ (Figure 4A, 5D). Greater than $500 \mathrm{~m}$ from the crater mid-point the number of VBPs decreases to between 0 and $0.5 \times 10^{-2}$ VBPs per $\mathrm{m}^{2}$ in most azimuths. The distribution of VBPs also shows directionality in the S and SSE azimuths where a greater number of VBPs were deposited between 300 and $500 \mathrm{~m}$ from the crater mid-point than in other azimuths (VBP densities ranging 124-3.4 $\times$ $10^{-2} \mathrm{~m}^{-2}$ compared to $23-0 \times 10^{-2} \mathrm{~m}^{-2}$, respectively) (Figure 4A). The E and ESE azimuth also have more VBPs at $400 \mathrm{~m}$ from the crater mid-point than the SE. Conversely, Figure 5A shows the SE having the largest median VBP diameter at $300 \mathrm{~m}$ that decreases away towards the ESE and SSE, creating a lobe that might indicate directionality. Median diameter was used as there are large VBP outliers that skew the mean value. Analysis of the size distribution also revealed an increase in median diameter at $500 \mathrm{~m}$ following a trend of decreasing size in the SSE azimuth.

The total October distribution shows similar patterns as the two-month distribution. From 30 mapping squares ( $400 \mathrm{~m}^{2}$ areas) 5481 VBPs were mapped. VBPs ranged from 3 to $353 \mathrm{~cm}$ in diameter with an average of $34 \mathrm{~cm}$. VBP spatial density decreases with distance from the crater from an average of $138.5 \times 10^{-2} \mathrm{~m}^{-2}$ at $200 \mathrm{~m}$ from the crater mid-point to $4 \times 10^{-2} \mathrm{~m}^{-2}$ at $700 \mathrm{~m}$, though not as rapidly as seen in the twomonth distribution (Figure 4B and 5D). When analysed in azimuths we see a general decrease in density along all azimuths, though at some point along all but the $\mathrm{E}$ and ENE azimuths, an increase in density is observed. For example, in the $\mathrm{S}$ azimuth, density decreases from $72.25 \times 10^{-2} \mathrm{~m}^{-2}$ at $400 \mathrm{~m}$ from the crater mid-point to $16.5 \times 10^{-2} \mathrm{~m}^{-2}$ at $500 \mathrm{~m}$ distance. Density then increases to $32.75 \times 10^{-2} \mathrm{~m}^{-2}$ at $600 \mathrm{~m}$ from mid-point and then decreases again with distance. Similar to the two-month distribution, VBP deposition is greater towards the S-SSE and E-ESE in contrast to the SE at most distances except at $400 \mathrm{~m}$ from mid-point where 

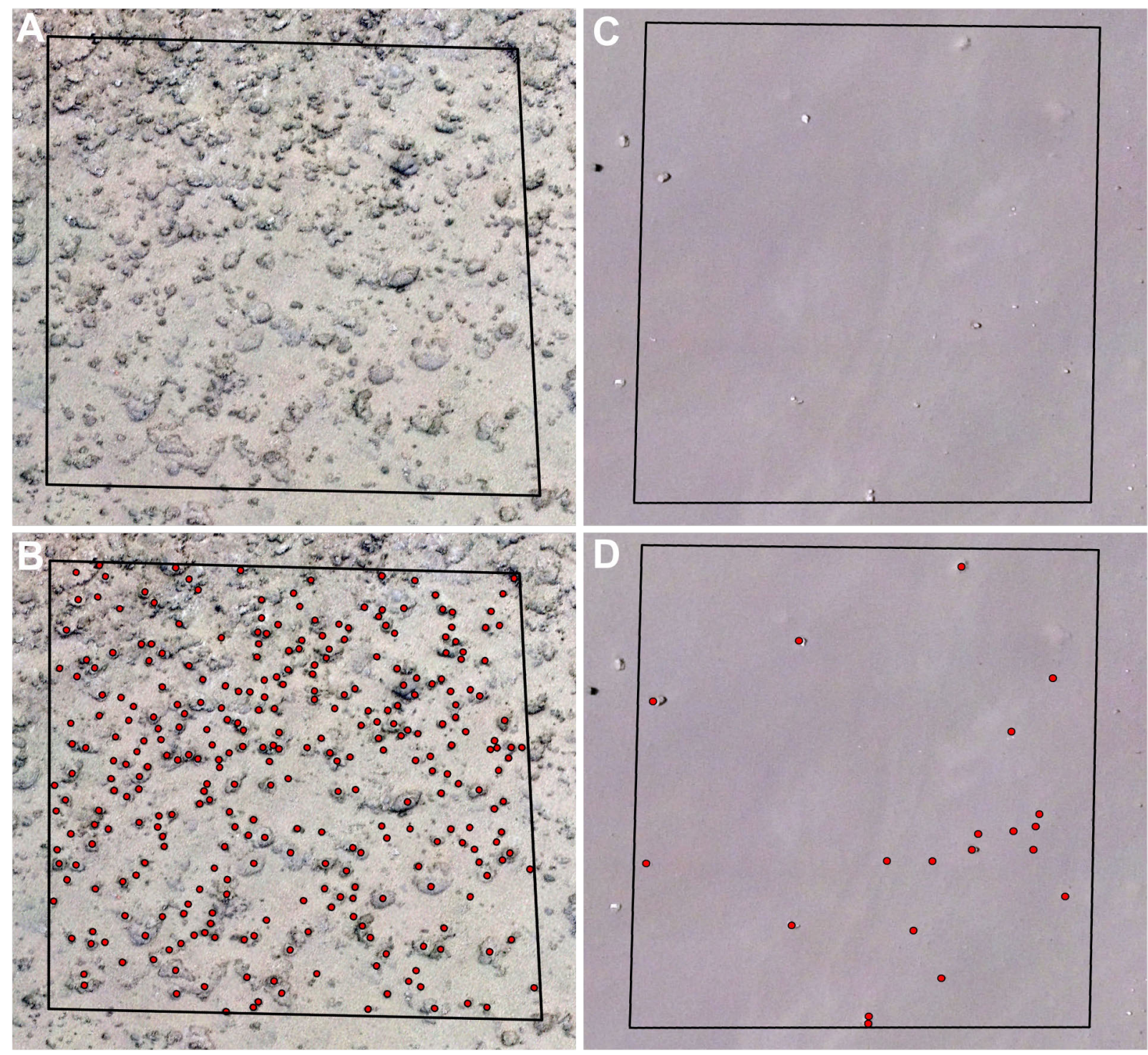

Figure 3: $20 \times 20 \mathrm{~m}$ mapping squares showing pre- $([\mathrm{A}]$ and $[\mathrm{C}])$ and post- $([\mathrm{B}]$ and $[\mathrm{D}])$ VBP identification from the October aerial images. [A] and [B] are located $300 \mathrm{~m}$ away from the crater mid-point in the SSE. [C] and [D] are $500 \mathrm{~m}$ away from the crater mid-point in the east.

it is at similar densities to the S and SSE (Figure 4B).

Analysing the October size distribution at varying distances and azimuths from the crater shows higher median VBP diameters to the SE at 300 and $500 \mathrm{~m}$ from crater mid-point that decrease away towards the ESE and SSE (Figure 5B). At $400 \mathrm{~m}$ from the crater mid-point, the ENE has the largest median diameter that decreases towards the $\mathrm{E}$ and NE, potentially indicating two lobes towards the SE and ENE (Figure 5B). The October distribution shows a general decrease of median VBP size with distance from crater mid-point until $600 \mathrm{~m}$ where VBP size begins to increase (Figure $5 \mathrm{C}$ ). Increasing diameters following a general decreasing trend is also seen in the S, SSE, and SE azimuths (Figure 5B).

\subsection{Eruption dynamics}

Over 10 hours (between 30 July and 1 August) of GoPro footage was collected, capturing 758 explosions. On average, 68 explosions occurred per hour $\left(\mathrm{hr}^{-1}\right)$, with 42 $\mathrm{hr}^{-1}$ from South Crater and $27 \mathrm{hr}^{-1}$ from North Crater. Each explosion was classified small, moderate or large, the vent origin noted (Table 1), and what style of eruption it was. As described earlier, the larger the explosion, the higher the VBPs are ejected vertically. Subsequently, a larger explosion has the ability to eject VBPs further from the vent area. Eruption styles included ballistic, ballistic with a tephra plume, tephra plume, and gas. To compare eruption frequency over the three days we normalised the number of small, moderate and large explosions each day to a 13-minute time period as this was the longest period of time explosions were 


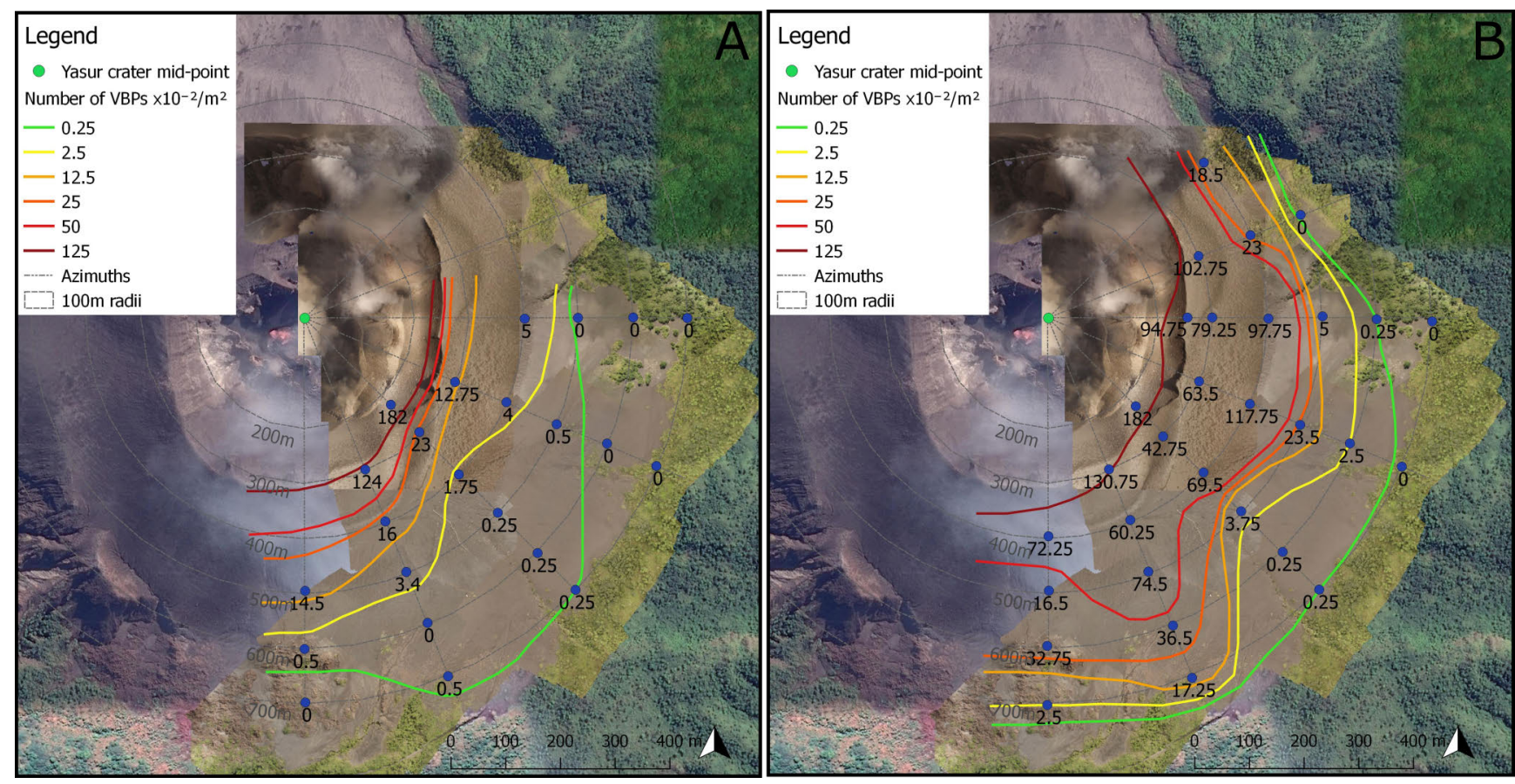

Figure 4: VBP spatial density from deposition over two months [A] and all VBPs on the ground in the later October images [B]. Blue circles indicate the number of VBPs $\times 10^{-2}$ per $\mathrm{m}^{2}$ in a mapping square. The aerial imagery captured from the two trips is layered beneath the map contours. Background image (C) 2019 Google.

recorded on 1 August. Therefore, the normalised eruption frequency provides the average number of explosions that occur over 13 minutes on that day. A marked increase in the frequency of large events is noted on 1 August (on average 13 large explosions per 13-minute period) compared to the previous days (on average 1 large explosion per 13-minute period on 30 July and 5 large explosions per 13-minute period on 31 July). Additionally, an increase in the number of explosions from the south crater vs the northern crater was noted. The frequency increased from 5 explosions per 13 minutes (30 July) and 14 explosions per 13 minutes ( 31 July) to 20 explosions per 13 minutes on 1 August. Seismic and infrasound data over this time also show an increase in explosivity (Figure 6). This can be more clearly seen in the infrasound record (Figure 6A and 6B) where on day 5 (1 August) there is a noticeable increase in peak event and total (RIAM) waveform amplitude. Highlighted in blue in Figure 6A are the video observed explosions from Table 1 . On average small explosions produce a peak pressure of 6.71 $\mathrm{Pa}$, increasing to 13.6 Pa for moderate explosions and 27.7 Pa for large explosions. Eruptive activity therefore is not steady and can fluctuate over hours.

From our analysis of the GoPro footage over 30 July to 1 August period, most explosions were vertically directed $(40 \%)$. However, when the jet was angled, a SE directionality was the favoured direction from South Crater and S from North Crater (Figure 7). The SE directionality from South Crater is also evident in the acoustic radiation recordings over the same time pe- riod, presented in Jolly et al. [2017]. No relationship between explosivity and directionality was observed with between one third and one half of all explosion sizes (that directionality could be ascertained) having vertical jets and the rest directed towards an azimuth. Between the two trips from 5 September to the 16 October, observations were made daily for 1 hour a day of where VBPs were landing (rather than orientation of the jet as for the GoPro footage), indicating directionality favouring the south. This period of time is when most of the VBP deposition occurred that is recorded in the two-month mapped distribution and thus it was important to get an idea of the eruption directionality within this time. Figure $7 \mathrm{C}$ shows the azimuths where VBPs ejected from South Crater landed, with $39 \%$ landing to the south. Only two observations were made of VBP directionality from North Crater. On both occasions they were directed to the south. During the second trip from 16-20 October, general visual observations of eruption dynamics showed directionality to the south and east from South Crater and to the east from North Crater [Gomez and Kennedy 2018].

We also noted a changing directionality throughout individual eruption events on some occasions. For example, VBPs would be ejected toward the north at the start of the explosion and subsequently move towards the south in a spraying motion. This was also noted by Gaudin et al. [2014] in Strombolian explosions, where the mean ejection angle shifted up to $40^{\circ}$ in a single explosion. They theorise that this is due to the changing location of the bubble rupture point as the rupture area 

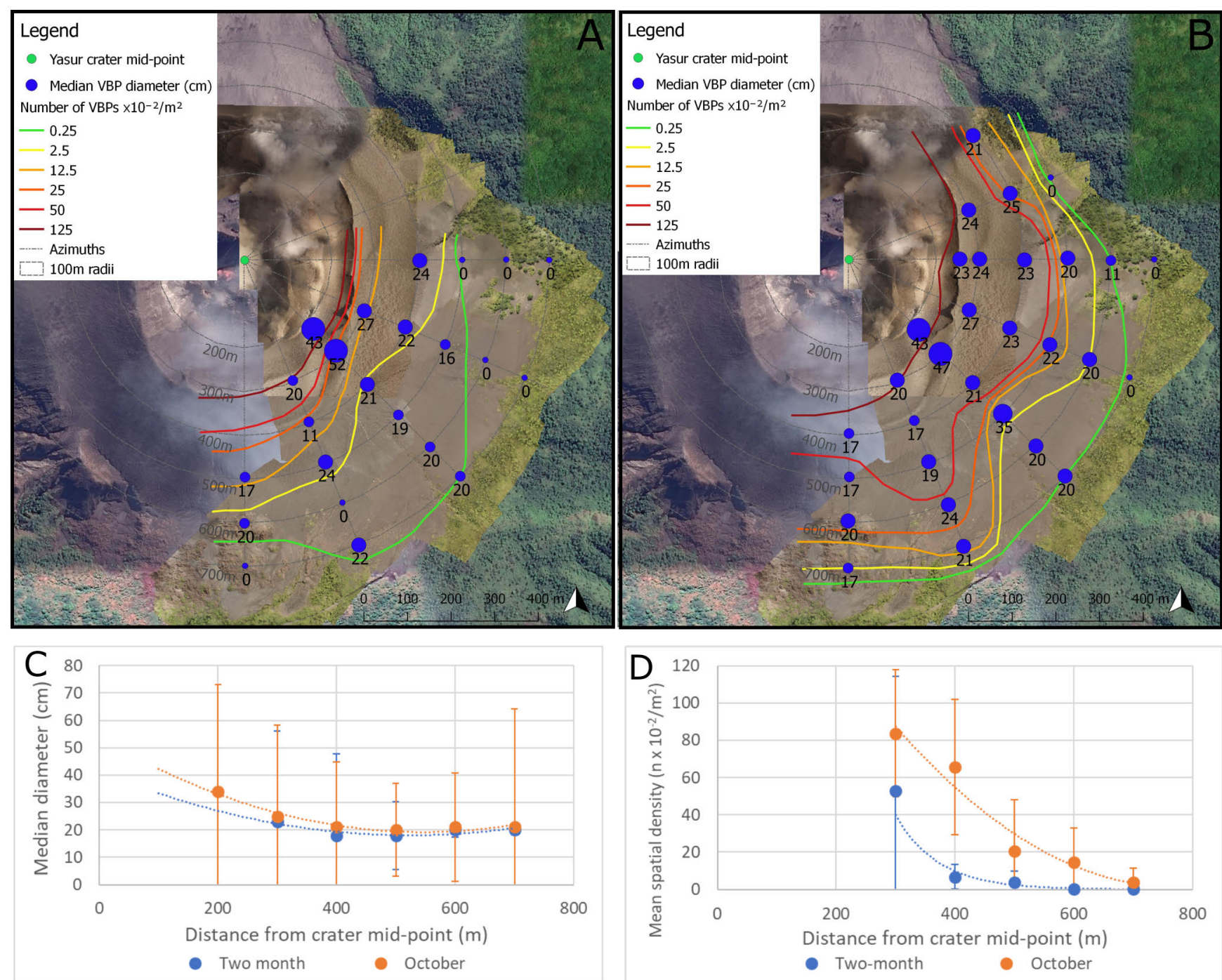

Figure 5: Relationship between median VBP size and spatial density with distance and direction from crater mid-point from the two-month $[\mathrm{A}]$ and October $[\mathrm{B}]$ distributions. Background imagery from drone imagery and (C) 2019 Google. [C] and [D] show the median diameter and mean spatial density with distance from crater midpoint for both distributions, irrespective of azimuth (with standard deviation error bars). A polynomial fit is applied to the two-month and October distributions in [C] with $r^{2}$ values of 0.7075 and 0.9573 , respectively. An exponential fit is applied for the two-month distribution and a polynomial fit to the October distribution in [D], with $r^{2}$ values of 0.9311 and 0.9548 respectively.

continues to open and increase in size. These instances have not been included in the directionality data presented here for simplicity, however, it is important to recognise that directionality is not fixed and can change even during one eruption event.

Not all explosions at Yasur have a VBP component, with $18 \%$ of the explosions recorded on the GoPro videos having no observable VBP component at all. This is an important consideration when using eruption frequency to assess VBP hazard.

Summarising our key results, we find that spatial density of VBPs decreases with distance from the crater, with this occurring more sharply in the two-month distribution than the October distribution, and that median VBP diameter decreases with distance from crater.
Directionality is evident in the spatial density mapping (S-SSE with a minor increase in density to the E), VBP size distribution analysis (SE and minor ENE) and video analysis (SE from South Crater and S from North Crater) and the daily visual observations, though they do not all agree. Video footage showed an increase in the frequency of large explosions from the 30 July to the 1 August, with large explosions capable of ejecting VBPs above the crater rim and creating a hazard for visitors. This is also seen in the infrasound and seismic record where amplitude increased on 1 August. 
Table 1 - Number and normalised frequency of small, moderate and large events, and the number and normalised frequency of explosions from each crater recorded on GoPros between 30 July and 1 August. Explosion frequency has been normalised to a 13 minute time period (the length of time explosions were recorded for on 1 August) as each day the length of time explosions were recorded for differed. Peak pressure recorded on infrasound station YIB22 was found for each video recorded explosion and the average and standard deviation of all explosions categorised into small, moderate or large was calculated.

\begin{tabular}{ccccccccc}
\cline { 2 - 8 } & \multicolumn{2}{c}{$30 / 07 / 2016$} & \multicolumn{2}{c}{$31 / 07 / 2016$} & \multicolumn{2}{c}{$1 / 8 / 16$} & \multicolumn{2}{c}{ Peak pressure (Pa) at YIB22 } \\
\cline { 2 - 8 } & No. & Normalised & No. & Normalised & No. & Normalised & Average & SD \\
\hline Small & 153 & 5 & 223 & 13 & 2 & 2 & 6.71 & 7.28 \\
Moderate & 90 & 3 & 146 & 8 & 10 & 10 & 13.6 & 14.6 \\
Large & 32 & 1 & 83 & 5 & 13 & 13 & 27.7 & 20.6 \\
\hline North & 131 & 5 & 212 & 12 & 5 & 5 & & \\
South & 143 & 5 & 241 & 14 & 20 & 20 & & \\
\hline Total & 274 & 453 & 25 &
\end{tabular}

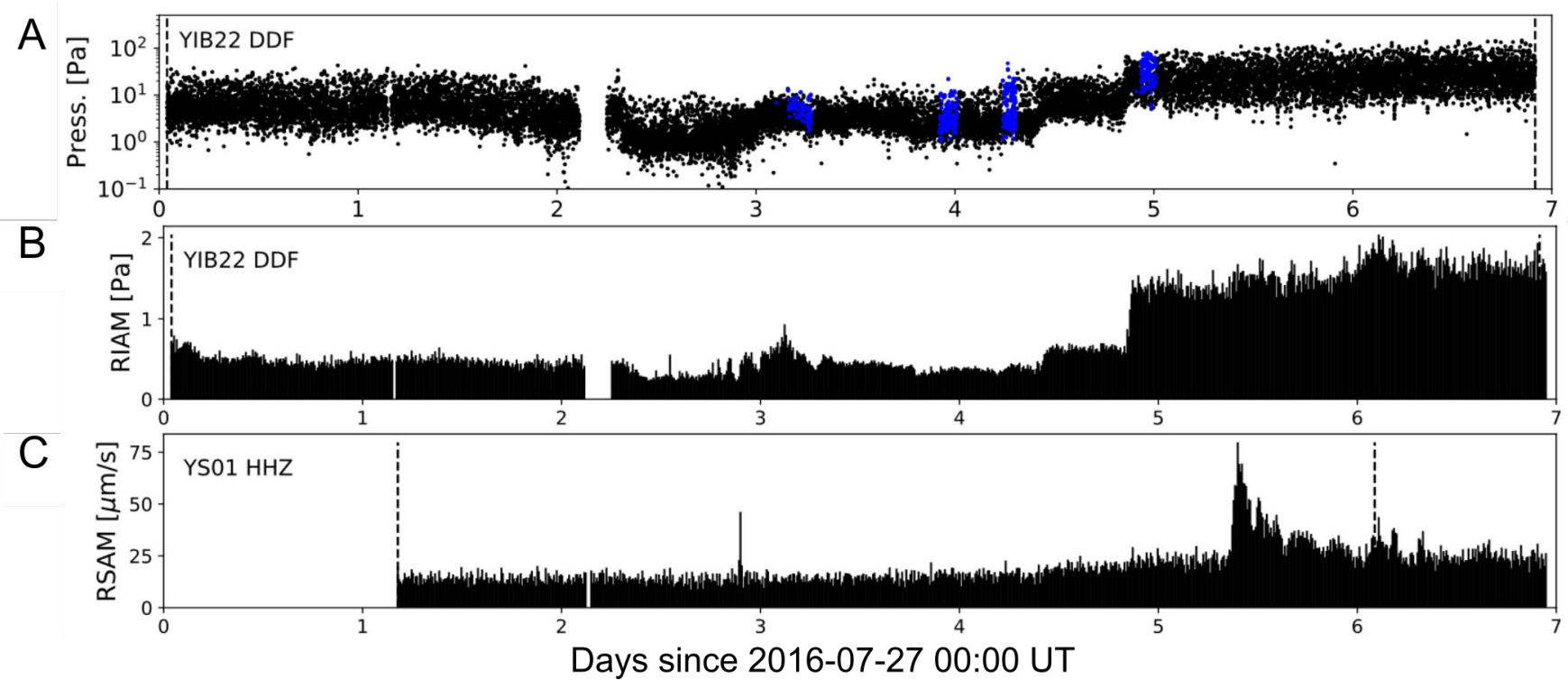

Figure 6: Infrasound and seismic amplitude metrics from a temporary co-located infrasound station (YIB22) and broadband seismometer (YS01) approximately $700 \mathrm{~m}$ from the summit vents. A shows peak event amplitudes for unfiltered infrasound data at YIB22. Blue symbols in A show infrasound amplitudes at YIB22 corresponding to the explosions analysed in video data in this study (see Table 1). Vertical dashed lines represent times of network completion for coincident triggers. B shows 10-minute Real-Time Infrasonic Amplitude (RIAM) and C shows Real-Time Seismic Amplitude (RSAM) values at YIB22 and YS01, respectively.

\section{Discussion}

While VBPs are primarily transported through the air on ballistic trajectories, two other factors can cause further transport after impact. The first is bouncing or rolling. This has been observed on Ngauruhoe [Allen 1948], Tungurahua [Bernard 2018], Kỉlauea [Swanson et al. 2012] and Stromboli [Taddeucci et al. 2017] and can result in the VBP coming to a complete stop tens to hundreds of metres from its original landing position [Bernard 2018; Pistolesi et al. 2008; Rosi et al. 2006]. This typically occurs on the slopes of a volcano, observed on slopes $>15-20^{\circ}$ at Alaid Volcano
[Steinberg and Lorenz 1983] and between $31^{\circ}$ and $38^{\circ}$ on Etna [McGetchin et al. 1974]. Secondly, VBPs can fragment on impact with the ground and the ejecta from this can travel metres away from the original landing/fragmentation site ( $>5 \mathrm{~m}$ by Taddeucci et al. [2017]; tens of metres at Stromboli by Rosi et al. [2006]; $28 \mathrm{~m}$ at Shinmoedake by Maeno et al. [2013]; $100 \mathrm{~m}$ at Ngauruhoe by Nairn and Self [1978]). Therefore, mapped VBP distributions will often reflect all transport mechanisms as it is often difficult to determine if these additional transport mechanisms have occurred, especially in areas of high VBP spatial densities.

The VBP distributions mapped from the aerial pho- 

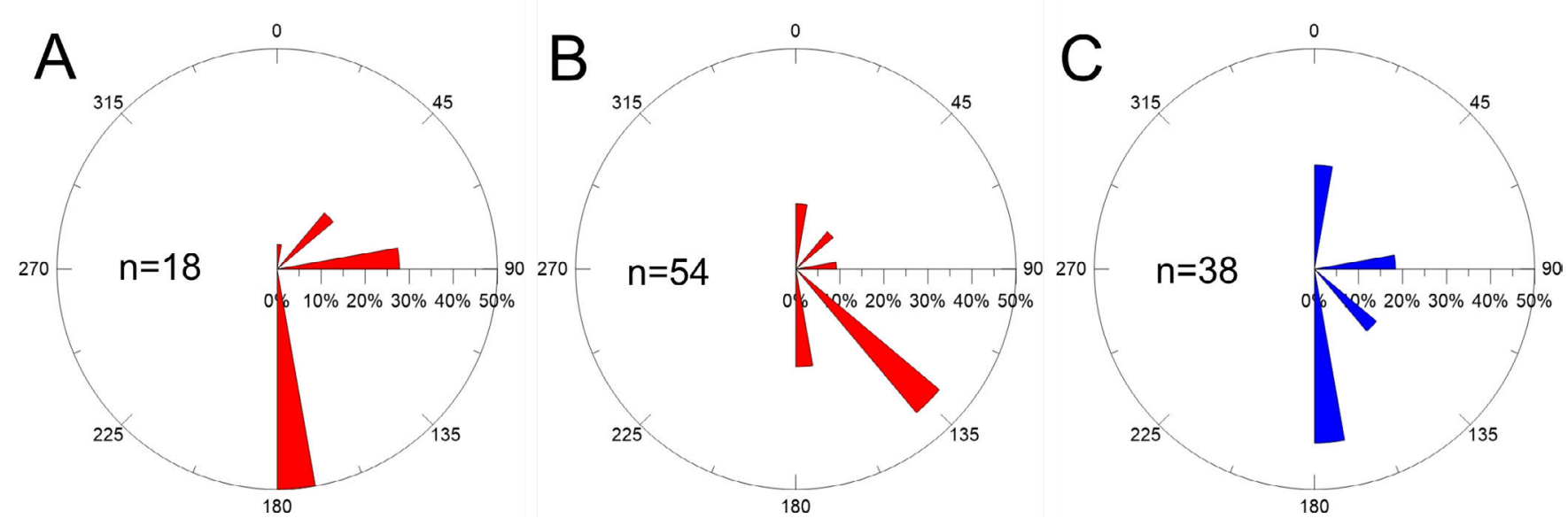

Figure 7: Directionality of explosions. $[\mathrm{A}]$ and $[\mathrm{B}]$ show the percentages of individual explosions that are directed in varying directions from North Crater [A] and South Crater [B] recorded on the GoPros over three days (31 July to 1 August 2016). The explosion count is lower than that given in Table 1 as the plots only show directed explosions, not those vertically directed or where direction could not be ascertained. [C] shows the directionality from South Crater seen from the observational logs from 5 September to 16 October 2016. The rose diagram bin thicknesses and gaps between bins are not representative of the resolution of the angle of explosion direction.

tos are the products of both the North and South Craters. The frequency of explosions from both craters, the lack of temporal sampling and the varying explosion directionalities make it difficult to assign specific vents to a distribution. However, it is likely that the higher densities in the S-SSE come from South Crater and those in the E from the North Crater. This deduction is based on the dominant explosion directionalities observed from video records and the observational logs and the greater distance VBPs from North Crater need to travel when directed toward the S-SSE.

\subsection{Decreasing median VBP size with distance from the crater}

The relationship between VBP size and distance travelled from source has been discussed in the literature with both increasing and decreasing size with distance observed. Taddeucci et al. [2017] summarise this literature to say that an increase in VBP size with distance is observed in many ash and block rich Vulcanian eruptions [Druitt et al. 2002; Fitzgerald et al. 2014; Minakami et al. 1969; Self et al. 1980; Steinberg 1974; Steinberg 1976] and a decrease in size with distance is usually observed in phreatomagmatic eruptions [Lorenz 1970; Novellis and Luongo 2006; Self et al. 1980; Waitt et al. 1995]. The former is hypothesised to be because all VBPs exit the vent at similar velocities and due to inertia, larger VBPs travel further while smaller VBPs are more greatly affected by drag and impact closer to the vent [Bertin 2017; Fagents and Wilson 1993; Novellis and Luongo 2006; Taddeucci et al. 2017]. For the latter, VBPs ejected in a gas stream may decrease the effects of drag on particles allowing smaller ones to travel higher than larger ones before dropping out of the stream and therefore travelling further than their larger counterparts [Kilgour et al. 2019; Lorenz 1970; Novellis and Luongo 2006; Self et al. 1980; Taddeucci et al. 2017]. For clarity, we term the increase in VBP size with distance as a normal distribution, and a decrease in VBP size with distance, a reverse distribution. VBP fields can also show no evident size trend [Mastin 1991; Taddeucci et al. 2017]. Taddeucci et al. [2017] attribute this to three reasons: not all VBPs are ejected with the same velocity in an eruption; overlapping VBP distributions either from multiple eruptions or multiple vents; and VBP collisions.

However, VBP size-distance relationships have not been discussed in relation to Strombolian eruptions. As Strombolian explosions tend to be frequent (up to $9 \mathrm{hr}^{-1}$ at Stromboli [Harris and Ripepe 2007]) and typically deposit bombs closer to the vent, the risk of being impacted while conducting fieldwork is high and is likely the main reason the size-distance relationship has not been investigated. A literature search resulted in two references where a relationship was found. Gurioli et al. [2013] note that in the 21 January 2010 eruption at Stromboli, thermal video shows 'a leading spray of smaller bombs, quickly followed by an emission of larger bombs that attained lower heights and fell closer to the vent than those of the first spray'. Andronico and Pistolesi [2010] report pumiceous clast sizes between 7 and $20 \mathrm{~cm}$ in the summit area of Stromboli ( $\sim 90$ m.a.s.1.) that reduce to an average long axis of the five largest clasts of $11 \mathrm{~cm}$ at $650 \mathrm{~m}$.a.s.l. from the $24^{\text {th }}$ November 2009 eruption. Both papers show a reverse distribution. Bombrun et al. [2015] also recorded lower initial ejection velocities of larger projectiles compared to smaller projectiles at Stromboli volcano. Strombolian eruptions are driven by gas slugs, providing the 
gas stream needed to reduce drag on smaller projectiles [Harris et al. 2012; Taddeucci et al. 2015]. This is likely the reason for the reverse distribution described in this paper and seen in the aforementioned publications.

Rolling and bouncing of VBPs on slopes post-impact may be a factor influencing the VBP size distribution. The base of the slope may have a greater proportion of larger VBPs than on the slope itself due to the momentum of rolling and bouncing VBPs. This is observed in rockfalls and talus slopes [Evans and Hungr 1993]. However, we observe a more complex relationship. Both increases and decreases in median VBP diameter are observed at the base of the cone compared to those on the cone in Figure 5A and 5B. Increases are noted in the SSE and ENE azimuths in the October distribution and in the SSE and SE in the two-month distribution. Decreases in median diameter are noted in all other azimuths. Whilst post-impact rolling and bouncing might influence the size distribution of VBPs on slopes causing larger VBPs to accumulate at the base of slopes, it is not clearly established within this data. Though increases in the median VBP diameter at the base of slopes were observed in some azimuths, this does not change the general decreasing size with distance relationship observed in the mapped distribution over the whole mapped area (from the vent area to 700 $\mathrm{m}$ distance). Nevertheless, larger VBPs rolling downhill on the slope could bias the average diameter towards higher values than that expected if only considering the point of first impact.

There is potential for VBP fragmentation to occur on impact with the ground which may affect the recorded size distribution or what is thought to be the size distribution of original VBPs. However, due to the high spatial density of VBPs on the cone it is near impossible to determine whether they have fragmented or not and therefore how fragmentation contributes to the size distribution. This may be a future research avenue in which the contribution of fragmentation to the size distribution is quantified.

\subsection{Changing spatial density with direction around} the crater

We see a change in spatial density from the south to the east, with higher densities in the S-SSE and ESE-E than the SE. Four main factors might influence where VBPs cluster or appear to cluster: (1) topography [Kilgour et al. 2019], (2) preservation of the deposit (3) VBP fragmentation and (4) eruption directionality [Gurioli et al. 2013; Kilgour et al. 2010]. A topographic high or steep sided crater wall may block VBP deposition as VBPs may not be able to reach heights capable of landing on the other side of the topography or angled VBPs may get blocked by steep sided crater walls. There does not appear to be any topographic shadowing affecting VBP deposition in the SE from South Crater or North Crater. The height of the crater rim is the same in the
$\mathrm{SE}$ as the ESE ( 320 $\mathrm{m})$, though is $10 \mathrm{~m}$ and $35 \mathrm{~m}$ higher in the SSE and S respectively when measured from the crater mid-point. Therefore, if the SE were shadowed we should see similar densities to the SE in the ESE and lower densities in the SSE and S. Analysing the ability of VBPs to be ejected from the vents uninhibited by crater walls reveals that VBPs ejected at angles $\geqslant 34^{\circ}$ from horizontal could escape the crater from the ESE to the SSE (Figure 8). The angles were measured from the middle of the North and South Craters respectively, rather than the all-encompassing crater mid-point to be as accurate as possible. In Strombolian explosions ejection angles are typically close to vertical (within $5^{\circ}$ from vertical at Stromboli [Chouet et al. 1974]; around $72^{\circ}$ at Mt Etna [Gouhier and Donnadieu 2011]; $70-85^{\circ}$ at Stromboli [Pistolesi et al. 2008]) with $80-90 \%$ of particles ejected within $20^{\circ}$ of the ejection axis [Chouet et al. 1974; Gouhier and Donnadieu 2010]. If we use the lower end of the reported average ejection angles $\left(72^{\circ}\right)$ and add on $20^{\circ}$ for the dispersion cone, all VBPs would successfully clear the ESE-SSE crater walls.

Topography may also impact the preservation of the original spatial density (landing positions). Steeper slopes may cause the occurrence of bouncing or rolling downhill post-impact [McGetchin et al. 1974; Steinberg and Lorenz 1983] which may present as greater spatial densities at the base of slopes than on the slopes themselves. Analysis of this relationship shows mixed results. In the October distribution (Figure 9B), we do not see higher densities at the base of the cone in the $\mathrm{S}$ and SE at $500 \mathrm{~m}$ distance $\left(16.5\right.$ and $3.75 / \mathrm{m}^{2}$ respectively) compared to on the flank at $400 \mathrm{~m}$ (72.25 and $69.5 / \mathrm{m}^{2}$ respectively) where there are greater slope angles. It is also not seen in the $\mathrm{E}$ at $250 \mathrm{~m}$ at the top of the flank $\left(94.75 / \mathrm{m}^{2}\right)$ compared to the base of the slope partway down the cone at $300 \mathrm{~m}\left(79.25 / \mathrm{m}^{2}\right)$. However, we do see this relationship in the E and ESE ( 97.75 and $117.75 / \mathrm{m}^{2}$ respectively) at $400 \mathrm{~m}$ at the base of the cone compared to 79.25 and $63.5 / \mathrm{m}^{2}$ at $300 \mathrm{~m}$ respectively. Higher spatial densities on the flanks compared to the base of the cone are also seen in the two-month distribution (Figure 9A). In the ESE we see a spatial density of $12.75 / \mathrm{m}^{2}$ at the top of the flank (at $300 \mathrm{~m}$ from the crater mid-point) compared to $4 / \mathrm{m}^{2}$ at the base (at $400 \mathrm{~m}$ ). The SE also has this pattern at $400 \mathrm{~m}$ and 500 $\mathrm{m}$. It is possible that higher densities at the base of the cone compared to the flank occur in the E, SSE, and S though we do not have flank densities to compare this to. Additionally, the azimuths that have higher spatial densities at the base of the cone are not the same ones that have higher median diameters at the base, leading to further uncertainty over the contribution of rolling and bouncing to larger scale spatial densities and size distribution.

We also see a lower spatial density in the SE at 300 $\mathrm{m}$ from the crater mid-point compared to the same distance in the ESE and SSE (Figure 4B). This area is on the side of the crater rim dipping in toward the vents 

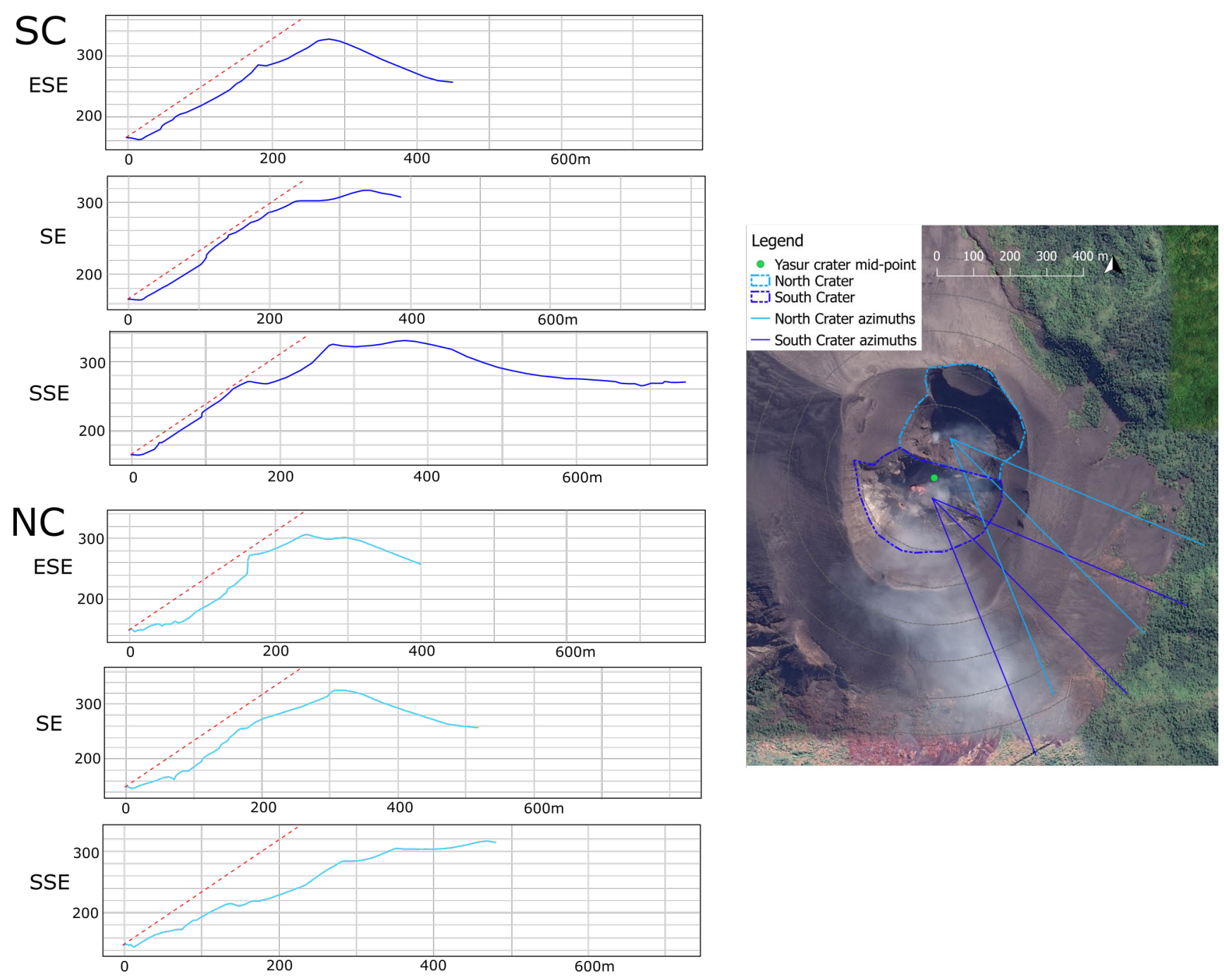

Figure 8: Topographic profiles of the crater rim and walls measured from the centre points of North Crater (NC) and South Crater (SC) along azimuths illustrated on the map, created from combining DEMs from the two trips. The red hatched line indicates $34^{\circ}$, the minimum angle that VBPs would clear the crater walls. Background imagery (C) 2019 Google.

(Figure 10). Landing on the vent-dipping side might explain lower densities in the SE at $300 \mathrm{~m}$ as the VBPs might land and then either roll back into the crater or stop on lower part of the inner crater rim. None of the other mapping squares at a $300 \mathrm{~m}$ distance are on a slope dipping towards the crater-the others are either at the base of the inner rim or are on the crater rim where it is flatter. We see three examples of empty impact craters with similar sized VBPs downhill (in toward the inner rim/crater) in the mapping square, as well as multiple cases of VBPs being on the edge of their impact craters in the direction of maximum slope towards the base of the inner rim (Figure 10). It is evident that bouncing and rolling occurs and affects spatial distribution patterns, but it is unclear to what extent the overall spatial distribution is affected.

The deposition of tephra fall has the ability to impede preservation of the VBP field and can affect the estimations of hazard and risk. Yasur not only erupts
VBPs but also smaller sized tephra fall (ash and lapilli). We see a complete burial of the VBPs in the JulyAugust images and deposition of new VBPs by the twomonth distribution in the SE $200 \mathrm{~m}$ from the crater mid-point. Tephra fall deposition could also contribute to the lower spatial densities seen in the SE where windblown tephra may have been deposited. To assess this possibility, we looked at the number of VBPs that were mapped in the July-August images but were no longer visible in the October images (Figure 11) and the wind directionality over the mapping period. Of the VBPs mapped in the July-August orthophotos, $50 \%$ were not visible in the October orthophotos. When divided into distance and azimuth from vent area, it is apparent that the SE does not have an increased percentage of missing VBPs compared to other azimuths and thus it is unlikely that SE ash and lapilli tephra fall directionality or preservation issues are a main factor in the VBP azimuthal spatial distributions observed. Additionally, 


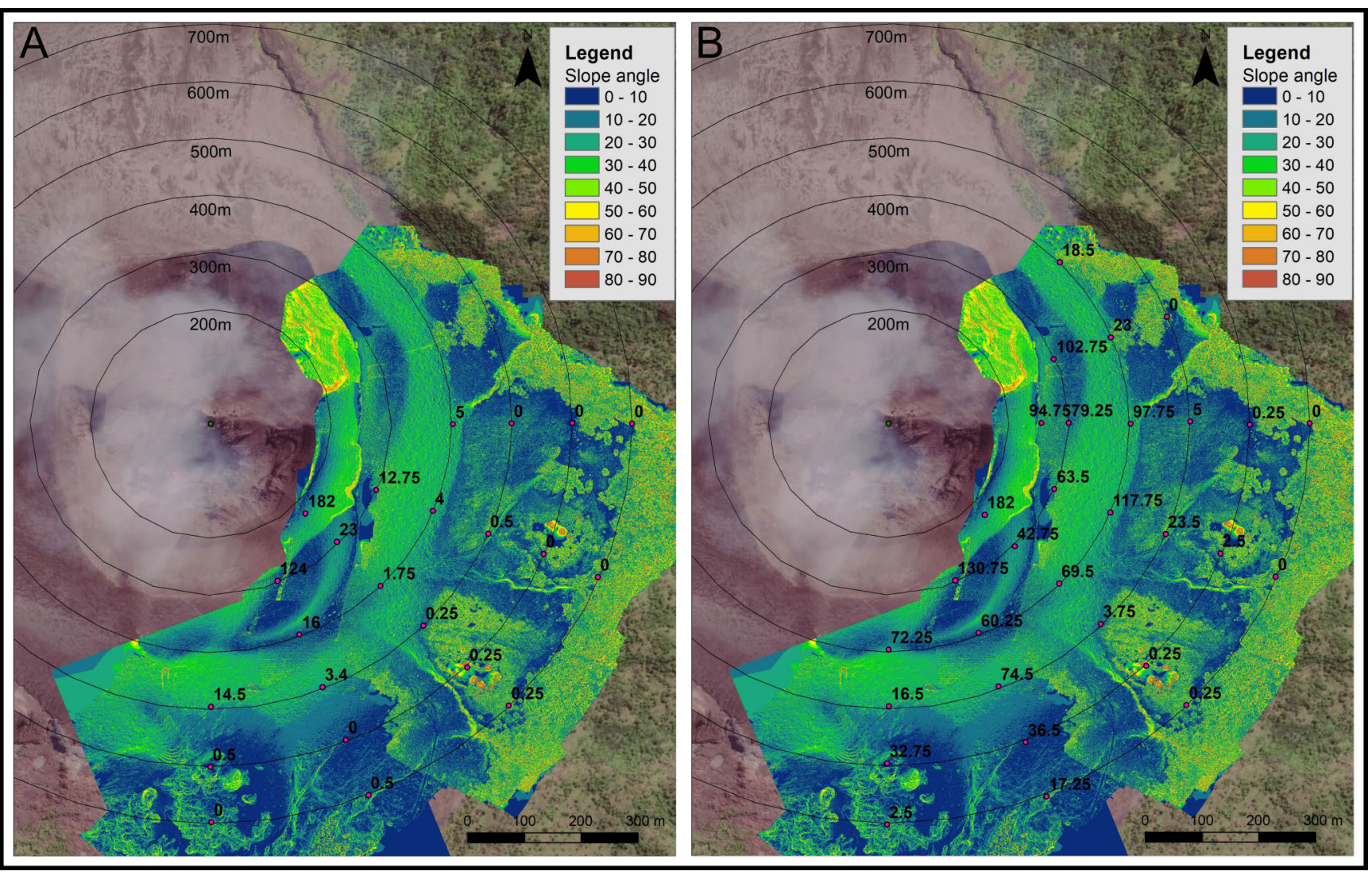

Figure 9: Maps showing the slope of the volcano overlaid with the mapped VBP spatial densities (number of VBPs $\times 10^{-2}$ per $\mathrm{m}^{2}$ ) from the two-month distribution [A] and the October distribution [B]. Background imagery sources: Esri, DigitalGlobe, GeoEye, Earthstar Geographics, CNES/Airbus DS, USDA, USGS, AeroGRID, IGN, and the GIS User Community.

the prevailing wind direction for Tanna is from the E-SE [Vanuatu Meteorology and Geohazards Department 2019a] which deposits windblown tephra fall in the opposite direction to the $\mathrm{W}$ to NW. The anemometer deployed on the south rim of the crater recorded N-SE winds throughout the July-August trip, though predominantly E-SE [see Jolly et al. 2017], that again would not be responsible for depositing ash and lapilli tephra fall preferentially to the SE. However, deposition of tephra fall in proximal areas of the cone is still likely, especially when wind speeds are low and this along with VBP deposition would explain the $50 \%$ of VBPs that could not be identified in the second survey in October.

As mentioned in the previous sections, VBPs can fragment on impact with the ground producing multiple smaller clasts that cluster around the area of impact, increasing the local spatial density. VBPs can also fragment in flight from collisions with other VBPs or due to ductile deformation [Taddeucci et al. 2017]. To investigate whether the mapped spatial densities were influenced by fragmentation, we divided each mapping square from the October distribution into four $10 \times 10 \mathrm{~m}$ squares and calculated the standard deviation for each mapping square. High standard devia- tions could indicate large amounts of smaller particles created by fragmentation, if supported by visual evidence of fragmentation (clustering of small particles near an impact site). We found a range of standard deviations from 0.43 to 27.68 in each of the mapping squares. However, the high standard deviations were not found to be linked with visual evidence of fragmentation, and therefore we cannot conclude that fragmentation is a dominant processes controlling our size distribution. Video footage of the flank and the entire ballistic trajectory would help to corroborate the fragmentation and high standard deviation theory.

Directed eruptions can produce asymmetric VBP fields [Fitzgerald et al. 2014; Gurioli et al. 2013; Houghton et al. 2011; Kilgour et al. 2010]. From the observational logs taken over the two-month period (Figure 7C), more VBPs were reported landing to the south of the vents in South Crater (i.e. both on the southern crater wall and outside the crater rim to the south). These eruption directionality observations match the increased spatial density in the S and SSE in the mapped distributions, indicating that eruption directionality is the likely cause of the observed VBP spatial distributions. The E-ESE increase in spatial density seen in the mapped distribution can also be explained 


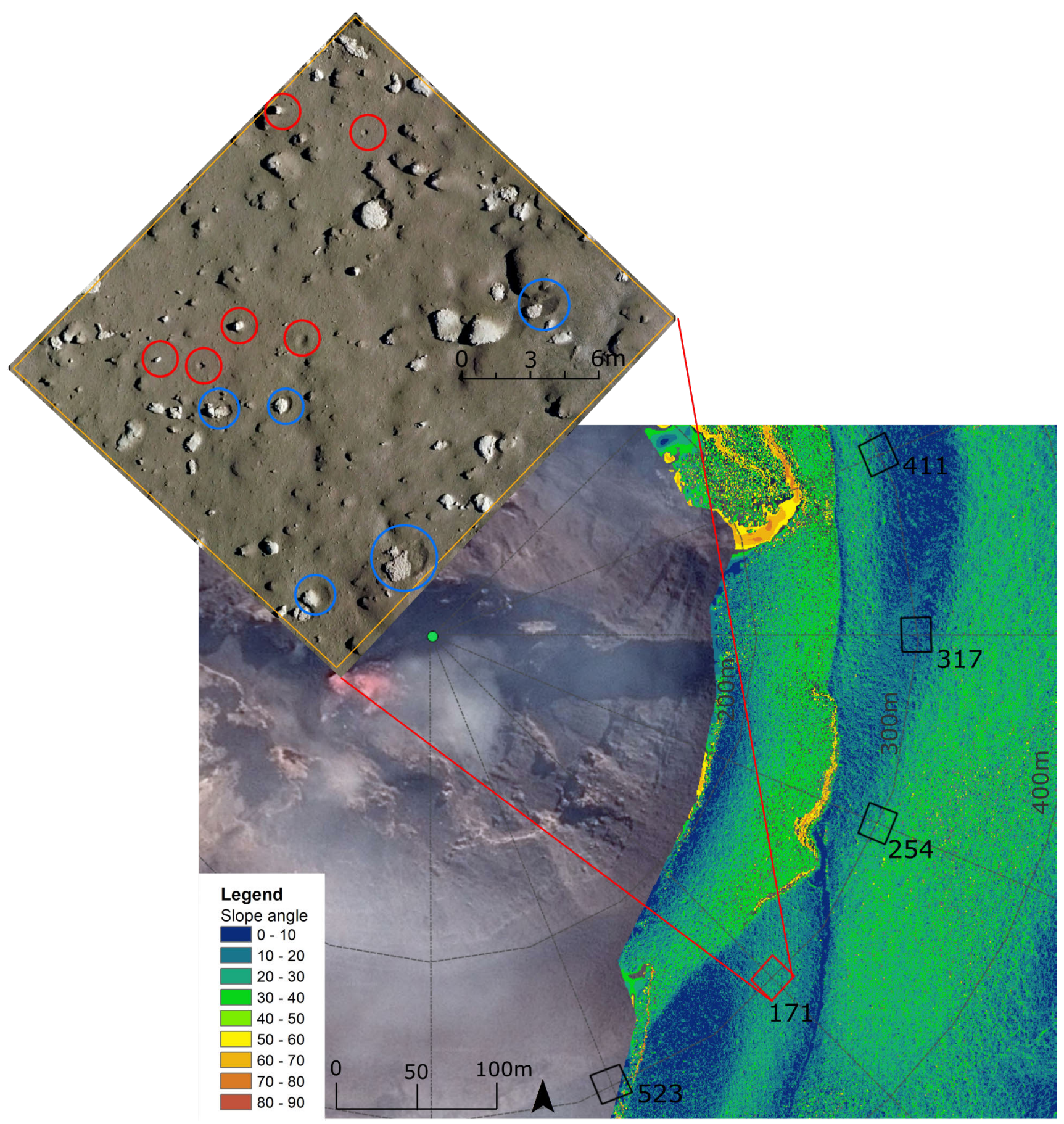

Figure 10: Slope angles of the areas mapped $300 \mathrm{~m}$ from crater mid-point, highlighting the location of a mapping square on the side of the crater dipping towards the vents. VBPs in the mapping square have bounced out of their craters (red circles show the crater and the likely VBP) or have slumped to the edge of their crater closest to the vents (blue circles). Background imagery of crater area (C) 2019 Google.

by explosion directionality, with $27 \%$ of the directed explosions recorded on video between 30 July and 1 August from North Crater going to the east (Figure 7A). Higher spatial densities in the SSE and $\mathrm{E}$ are also noted in maps produced following increased activity in 1994 [Global Volcanism Program 1995]. However, we observed from the 3-day video footage captured during the July-August fieldwork a predominantly SE direc- tionality (of those eruptions that were directed) from South Crater (Figure 7B) which is not supported in the mapped distributions (we would see an increased spatial density in the SE). This could be due to the short timeframe of recorded video (3 days) not representing the longer-term directionality. Salvatore et al. [2018] recorded variations in jet directionality over short timescales of hours to days at Stromboli from a 


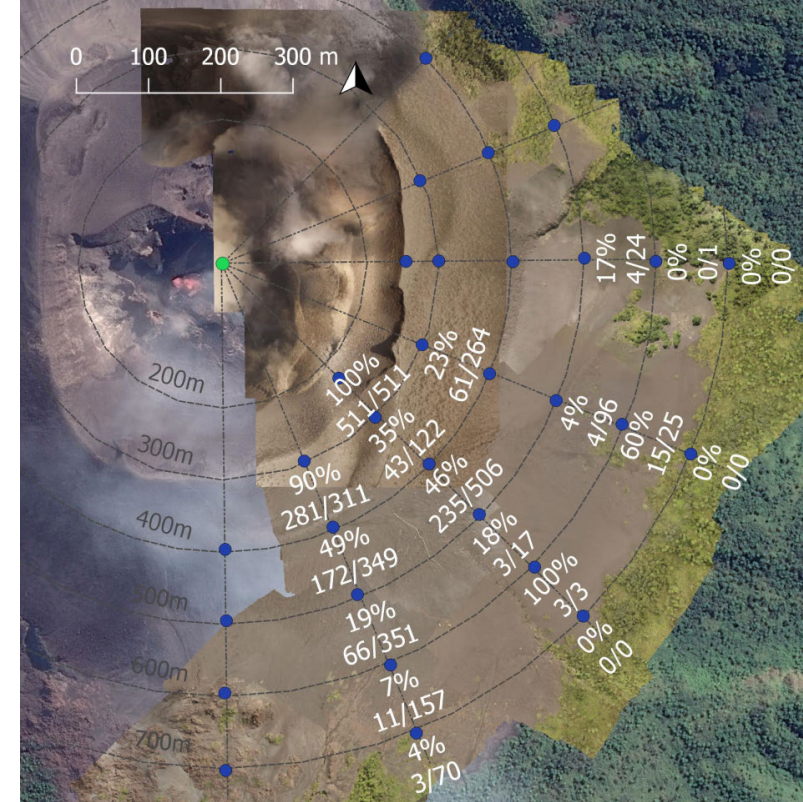

Figure 11: Number and percentage of VBPs missing from the October images that were mapped in the JulyAugust images out of the total mapped from the JulyAugust images. Five sites were excluded (500-700 m in the south azimuth and $400 \mathrm{~m}$ in the ESE and E) as photo resolution inhibited determining whether tephra fall did cover previously mapped areas. Background imagery behind drone imagery: ๑ 2019 Google.

four-year record and that this was the result of changes to vent size and morphology. Over longer timescales (months to years) vents were observed to migrate and merge. Both of these factors could cause the eruption directionality and asymmetry seen in our mapping.

In summary, VBP spatial density changes with direction from the crater. This is likely caused by explosion directionality and minimally by slope changes and VBP fragmentation on impact. Topographic shadowing was not observed from the NE to $S$ (though may affect the unmapped western side which is higher than the east and south), and ash and lapilli tephra fall and VBP burial of the VBP field does not explain the observed changes in spatial density with direction but does explain the lack of preservation of many VBPs. As our mapping of the field is limited to the NE to $\mathrm{S}$ (clockwise) we do not capture the VBP field around the entire volcano. However, we do capture the areas in which tourists and guides utilise and the predominant eruption directionalities, recorded during our field campaigns. Further work is needed to map the VBP distribution from the $S$ to the NE (clockwise) to ascertain the full picture of the VBP hazard at Yasur.

\subsection{Contrasting size, density, and directionality data}

A larger mean VBP diameter is observed at $300 \mathrm{~m}$ distance in the SE in both distributions and at $500 \mathrm{~m}$ in the October distribution compared to other azimuths. In the SE azimuth, we also observe the lowest VBP spatial density and highest proportion of eruption directionality from the GoPro videos. The contradicting GoPro eruption directionality and spatial density, as explained earlier, is likely due to the GoPro footage representing a small timeframe and not the longer-term preferential directionality. However, this does not explain the large clast size anomaly in the SE. We are unsure as to what is causing this. It could be the result of larger less frequent eruptions ejecting larger VBPs further and wider, depositing large clasts in the SE as well as in all other directions, in comparison to the more common smaller eruptions that are directed in other directions, depositing smaller VBPs in these areas. Unfortunately, our GoPro footage did not record any such sufficiently large events where large VBPs reached these distances.

\subsection{Differences in the density with distance trend be-} tween the two-month and October distributions

A decrease in the VBP spatial density with increasing distance from the vent area is evident in both the twomonth and October distributions. There are low VBP spatial densities in distal areas for the most part because fewer VBPs are ejected to this distance in the small frequent explosions. However, these densities are also affected by the presence of vegetation and the location of the ash plain at these distances. Though both distributions show this decreasing density with distance relationship, they do not follow the same trend. A steeper decrease is seen in the two-month distribution. This could be due to two factors. Firstly, the October distribution covers a longer time period where larger eruptions likely occurred over months to years prior to the survey date, ejecting a greater number of VBPs further than in the two-month period. Secondly, proximal ash and lapilli fall could be covering older VBPs in the two-month distribution (though the VBPs were still deposited within the two months).

\section{HAZARD AND RISK IMPLICATIONS}

Our results may have implications for risk management. Understanding which areas have higher densities of VBP impact and how the spatial density decreases with distance could be used to determine where transient visitors may be safer to visit or where infrastructure is sited.

The spatial density of VBPs reported here should be considered conservative due to burial of proximal deposits by subsequent tephra fall, masking the true deposition; hence the hazard to visitors may be underestimated. Preservation issues with VBP deposits (e.g. burial of deposits as witnessed here, but also erosion of craters by weather and other factors) show how time sensitive VBP mapping is to capture the true distribu- 
tion from an eruption.

This VBP hazard research does not encompass the hazard from larger eruptions which would likely produce a larger VBP field that may extend into the jungle at Yasur. Reports from a more explosive eruption period in June-July 1999 describe ejected VBPs reaching as far as $600 \mathrm{~m}$ from the nearest edge of the crater [Global Volcanism Program 1999]. This would require fieldwork at greater distances from the crater and modelling to understand the potential distributions. Further assessment would also be beneficial over a longer time period (e.g. 12-24 months), like that performed by Salvatore et al. [2018], to capture any temporal variability in eruption directionality and potentially eruption size, which may reduce the spatial variability seen in this study. We note the Vanuatu National Disaster Management Office, the government agency responsible for disaster risk reduction, have a permanent exclusion zone that includes the crater and the top of the flanks extending around from the viewing points. Additional 'zones' are restricted during periods of elevated seismic activity (monitored by Vanuatu Meteorology and Geohazards Department [VMGD]) associated with larger or more frequent explosions (Table 1 and Figure 6 show the correlation between elevated seismoacoustic activity and an observed increase in the proportion of larger explosions). Danger Zone A includes the cone and volcano viewing is only allowed from the carpark. Danger Zone B is an $\sim 500 \mathrm{~m}$ radius from the edge of the crater rim that includes the car park and parts of the ash plain [Vanuatu Meteorology and Geohazards Department 2019b]. As shown in Figure 6 and Table 1, acoustic sensors are highly complementary to the seismic and visual observations with regards to energy dynamics of eruptions and VBP hazard. Acoustic monitoring at the sole seismic station monitored by VMGD may add value to monitoring and risk decision making, though further investigation of its limitations is needed which is outside the scope of this study.

As well-known with volcanoes, past behaviour does not necessarily dictate future behaviour. This needs to be considered when using eruption directionality to assess potential VBP hazard areas (i.e. areas exposed to volcanic ballistic projectile deposition), which could then be used to inform where access on the volcano may be tolerable within risk management decision making. Our data shows that the VBP hazard is highly spatially variable, in part due to explosion directionality, but that directionality may vary significantly temporally. Therefore directionality results from this study alone should not be used as the basis for hazard and risk decisions. Longitudinal studies on directionality patterns are needed to determine the stability, usefulness and representativeness of directionality in VBP hazard and risk decision-making. In the interim, it may be more conservative and pragmatic to use spatial density and how this changes with distance from the vent to describe the hazard intensity and for a radius of a cer- tain distance around the vent based on spatial density to be used to define 'hazard areas' so that any future change in directionality is accounted for. In the past hazard areas have been defined by the maximum travel distance of a specific diameter VBP. However, as discussed earlier, eruptions can produce normal and reverse VBP distributions and thus setting a high or low diameter threshold could cause over or underestimation of travel distance depending on the eruption style. Combining these two approaches where spatial density of VBP deposition above a dangerous diameter is used as a measure to define hazard areas could also be considered in the future. Further investigation is needed to determine what measure is best to apply to characterise VBP hazard.

The VBP hazard mapping and analysis presented in this paper is intended to improve our understanding of the extent and distribution of VBP hazard from Strombolian eruptions. This study should not be used in isolation to guide or inform risk management decisions at Yasur or any other volcano. Rather this study provides data and analysis for one step (of many) in the process of assessing risk to visitors and infrastructure, which can contribute to informing decisions as to how the risk should be managed.

\section{Conchusions}

Understanding where VBPs land, their spatial density and size, and how this changes with distance and direction from the vent can inform more effective risk management. This is especially important on volcanoes that are frequently visited such as Yasur Volcano, Vanuatu. We used a drone to image part of the VBP field around Yasur and GoPro cameras and daily observations to record explosions. Mapping and analysis of the images and video revealed:

1) The spatial density of the VBPs decreased with increasing distance away from the crater

2) The median VBP diameter decreased with distance from the crater (evident up to $600 \mathrm{~m}$ distance), similar to that seen from Strombolian eruption deposits at Stromboli and also from phreatomagmatic eruptions around the world. This is likely due to the presence of a gas jet decreasing drag on particles, allowing smaller ones to travel higher and further than larger ones.

3) Higher spatial densities of VBPs are seen in the SSSE than in other directions. We attribute this to directionality in the explosions and not to topographic shadowing.

4) A different directionality was observed in the GoPro videos than in the daily observations and VBPs mapped from aerial photos. The mapping represents a longer time frame than the observations or 
videos and likely represents the longer-term directionality trend, showing that directionality is time variable.

5) Field preservation issues are apparent, with the burial of VBPs by further deposition of tephra fall. Therefore, VBP mapping is time sensitive after an eruption and delays in mapping will likely be accompanied by decrease in field preservation and result in an underestimation of VBP hazard.

When creating VBP hazard and risk maps or making risk management decisions at continuously erupting volcanoes it is important to remember that the hazard can vary over relatively small areas and over different time frames. Assessing the hazard over as much of the volcano as possible and over as long a time frame as possible will produce more effective results to subsequently base successful risk management decisions from.

\section{Acknowledgements}

This work was supported by a biennial grant (16/727) from the New Zealand Earthquake Commission (EQC). RHF was funded by a Ngāi Tahu Research Centre Doctoral Scholarship. RSM was supported by NSF grants EAR-1620576 and EAR-1847736. We thank Nick Key, Matt Cockcroft, Adrien Teissier, Janvion Cevuard, Athanase Worwor and Julius Mala for invaluable field assistance, and Sandrine Cevuard at VMGD for monitoring support. Seismic and infrasonic data analysis included the use of ObsPy [Beyreuther et al. 2010]. We are grateful to the editor Jamie Farquharson and two reviewers Benjamin Bernard and Fabian Wadsworth for their constructive comments and suggestions.

\section{Author COnTributions}

R.H. Fitzgerald analysed GoPro footage and catalogued explosions, mapped the VBP distributions and analysed the results, and wrote the manuscript. C. Gomez processed drone imagery and created the orthophotos and DEMs. R.S. Matoza provided the seismic and infrasound data and created Figure 6. B. Simons provided observation logs between two trips. E. Garaebiti coordinated fieldwork and provided local hazard management context. All authors assisted in discussions and writing of the manuscript.

\section{Data aVailability}

Orthophotos, DEMs, GoPro footage, eruption catalogue and VBP distribution shapefiles available on request from the corresponding author.

\section{COPYRIGHT NOTICE}

(C) The Author(s) 2020. This article is distributed under the terms of the Creative Commons Attribution 4.0 International License, which permits unrestricted use, distribution, and reproduction in any medium, provided you give appropriate credit to the original author(s) and the source, provide a link to the Creative Commons license, and indicate if changes were made.

\section{REFERENCES}

Alatorre-Ibargüengoitia, M. A., H. Delgado-Granados, and D. B. Dingwell (2012). "Hazard map for volcanic ballistic impacts at Popocatépetl volcano (Mexico)". Bulletin of Volcanology 74.9, pp. 2155-2169. Dor: 10 . 1007/s00445-012-0657-2.

Allen, L. (1948). "Activity at Ngauruhoe, April-May 1948". New Zealand Journal of Science and Technology 30, pp. 187-193.

Andronico, D. and M. Pistolesi (2010). "The November 2009 paroxysmal explosions at Stromboli". Journal of Volcanology and Geothermal Research 196.1-2, pp. 120-125. DoI: 10.1016/j. jvolgeores. 2010.06. 005.

Andronico, D., S. Scollo, and A. Cristaldi (2015). "Unexpected hazards from tephra fallouts at Mt Etna: The 23 November 2013 lava fountain". Journal of Volcanology and Geothermal Research 304, pp. 118-125. DoI: $10.1016 / \mathrm{j}$. jvolgeores.2015.08.007.

Bani, P. and M. Lardy (2007). "Sulphur dioxide emission rates from Yasur volcano, Vanuatu archipelago". Geophysical Research Letters 34.20. DOI: 10 . 1029 / $2007 \mathrm{gl030411.}$

Bani, P., A. Harris, H. Shinohara, and F. Donnadieu (2013). 'Magma dynamics feeding Yasur's explosive activity observed using thermal infrared remote sensing". Geophysical Research Letters 40.15, pp. 3830-3835. Dor: 10.1002/grl.50722.

Battaglia, J., J.-P. Métaxian, and E. Garaebiti (2016). "Families of similar events and modes of oscillation of the conduit at Yasur volcano (Vanuatu)". Journal of Volcanology and Geothermal Research 322, pp. 196211. Dor: 10.1016/j . jvolgeores.2015.11.003.

Baxter, P. J. and A. Gresham (1997). "Deaths and injuries in the eruption of Galeras Volcano, Colombia, 14 January 1993". Journal of Volcanology and Geothermal Research 77.1-4, pp. 325-338. DoI: $10.1016 /$ s0377-0273(96) $00103-5$.

Bernard, B. (2018). "Rapid hazard assessment of volcanic ballistic projectiles using long-exposure photographs: insights from the 2010 eruptions at Tungurahua volcano, Ecuador". Volcanica 1.1, pp. 49-61. DOI: $10.30909 / \mathrm{Vol} .01 .01 .4961$.

Bertin, D. (2017). "3-D ballistic transport of ellipsoidal volcanic projectiles considering horizontal wind field and variable shape-dependent drag coef- 
ficients". Journal of Geophysical Research: Solid Earth 122.2, pp. 1126-1151. DoI: 10.1002/2016jb013320.

Beyreuther, M., R. Barsch, L. Krischer, T. Megies, Y. Behr, and J. Wassermann (2010). "ObsPy: A Python Toolbox for Seismology". Seismological Research Letters 81.3, pp. 530-533. Dor: 10.1785/gssrl.81.3.530.

Blong, R. J. (1984). Volcanic hazards: a sourcebook on the effects of eruptions. Orlando: Academic Press.

- (1996). "Volcanic Hazards Risk Assessment". Monitoring and Mitigation of Volcano Hazards. Springer Berlin Heidelberg, pp. 675-698. DoI: 10.1007/9783-642-80087-0_20.

Bombrun, M., A. Harris, L. Gurioli, J. Battaglia, and V. Barra (2015). "Anatomy of a Strombolian eruption: Inferences from particle data recorded with thermal video". Journal of Geophysical Research: Solid Earth 120.4, pp. 2367-2387. DoI: 10.1002/2014jb011556.

Booth, B. (1979). "Assessing volcanic risk". Journal of the Geological Society 136.3, pp. 331-340. DOI: 10 . 1144 /gsjgs.136.3.0331.

Bower, S. M. and A. W. Woods (1996). "On the dispersal of clasts from volcanic craters during small explosive eruptions". Journal of Volcanology and Geothermal Research 73.1-2, pp. 19-32. DoI: $10.1016 / 0377-$ $0273(96) 00006-6$.

Breard, E., G. Lube, S. Cronin, R. Fitzgerald, B. Kennedy, B. Scheu, C. Montanaro, J. White, M. Tost, J. Procter, and A. Moebis (2014). "Using the spatial distribution and lithology of ballistic blocks to interpret eruption sequence and dynamics: August 62012 Upper Te Maari eruption, New Zealand". Journal of Volcanology and Geothermal Research 286, pp. 373386. DoI: $10.1016 / \mathrm{j}$. jvolgeores. 2014.03.006.

Brothelande, E. et al. (2016). "Structure and evolution of an active resurgent dome evidenced by geophysical investigations: The Yenkahe dome-Yasur volcano system (Siwi caldera, Vanuatu)". Journal of Volcanology and Geothermal Research 322, pp. 241-262. DoI: 10.1016/j. jvolgeores.2015.08.021.

Brown, S. K., S. F. Jenkins, R. S. J. Sparks, H. Odbert, and M. R. Auker (2017). "Volcanic fatalities database: analysis of volcanic threat with distance and victim classification". Journal of Applied Volcanology 6.1. Dor: 10.1186/s13617-017-0067-4.

Chouet, B., N. Hamisevicz, and T. R. McGetchin (1974). "Photoballistics of volcanic jet activity at Stromboli, Italy". Journal of Geophysical Research 79.32, pp. 4961-4976. Dor: 10.1029/jb079i032p04961.

Deligne, N. I., G. E. Jolly, T. Taig, and T. H. Webb (2018). "Evaluating life-safety risk for fieldwork on active volcanoes: the volcano life risk estimator (VoLREst), a volcano observatory's decision-support tool". Journal of Applied Volcanology 7.1. DoI: 10.1186/s13617๑18-0076-y.

Druitt, T. H., S. R. Young, B. Baptie, C. Bonadonna, E. S. Calder, A. B. Clarke, P. D. Cole, C. L. Harford, R. A. Herd, R. Luckett, G. Ryan, and B. Voight (2002). "Episodes of cyclic Vulcanian explosive ac- tivity with fountain collapse at Soufrière Hills Volcano, Montserrat". Geological Society, London, Memoirs 21.1, pp. 281-306. DoI: 10.1144/gsl . mem. 2002 . 021.01 .13$.

Endo, E. T. and T. Murray (1991). "Real-time Seismic Amplitude Measurement (RSAM): a volcano monitoring and prediction tool". Bulletin of Volcanology 53.7, pp. 533-545. DoI: 10.1007/bf00298154.

Erfurt-Cooper, P., H. Sigurdsson, and R. M. Lopes (2015). "Volcanoes and Tourism". The Encyclopedia of Volcanoes. Elsevier, pp. 1295-1311. Dor: 10.1016/ b978- ๑-12-385938-9.00075-4.

Evans, S. and O. Hungr (1993). "The assessment of rockfall hazard at the base of talus slopes". Canadian Geotechnical Journal 30.4, pp. 620-636. Dor: 10. 1139/t93-054.

Fagents, S. A. and L. Wilson (1993). "Explosive volcanic eruptions-VII. The ranges of pyroclasts ejected in transient volcanic explosions". Geophysical Journal International 113.2, pp. 359-370. Dor: $10.1111 / \mathrm{j}$. 1365-246x. 1993. tb00892.x.

Firth, C. W., H. K. Handley, S. J. Cronin, and S. P. Turner (2014). "The eruptive history and chemical stratigraphy of a post-caldera, steady-state volcano: Yasur, Vanuatu". Bulletin of Volcanology 76.7. Dor: 10.1007/ s00445- $014-0837-3$.

Fitzgerald, R. H., B. M. Kennedy, T. M. Wilson, G. S. Leonard, K. Tsunematsu, and H. Keys (2017). "The Communication and Risk Management of Volcanic Ballistic Hazards". Advances in Volcanology. Springer International Publishing, pp. 121-147. Dor: 10.1007/ 11157_2016_35.

Fitzgerald, R., K. Tsunematsu, B. Kennedy, E. Breard, G. Lube, T. Wilson, A. Jolly, J. Pawson, M. Rosenberg, and S. Cronin (2014). "The application of a calibrated 3D ballistic trajectory model to ballistic hazard assessments at Upper Te Maari, Tongariro". Journal of Volcanology and Geothermal Research 286, pp. 248262. Dor: 10.1016/j . jvolgeores . 2014.04.006.

Fudali, R. F. and W. G. Melson (1971). "Ejecta velocities, magma chamber pressure and kinetic energy associated with the 1968 eruption of arenal volcano". Bulletin Volcanologique 35.2, pp. 383-401. Dor: 10 . $1007 / \mathrm{bf02596963.}$

Gates, S. (2018). "Mapping and modelling phreatic ballistic fields at tourism hotspots: a methodological assessment at Tongariro and Whakaari (White Island) Volcanoes, New Zealand". MA thesis. University of Canterbury.

Gaudin, D., M. Moroni, J. Taddeucci, P. Scarlato, and L. Shindler (2014). "Pyroclast Tracking Velocimetry: A particle tracking velocimetry-based tool for the study of Strombolian explosive eruptions". Journal of Geophysical Research: Solid Earth 119.7, pp. 5369-5383. DOI: $10.1002 / 2014$ jb011095.

Global Volcanism Program (1995). "Report on Yasur (Vanuatu)". Bulletin of the Global Volcanism Network. 
Ed. by R. Wunderman. Vol. 20. 8. Smithsonian Institution. DoI: 10.5479/si.GVP. BGVN199508-257100.

- (1999). "Report on Yasur (Vanuatu)". Bulletin of the Global Volcanism Network. Ed. by R. Wunderman. Vol. 24. 7. Smithsonian Institution. Dor: 10.5479/ si. GVP. BGVN199907-257100.

- (2001). "Report on Masaya (Nicaragua)". Bulletin of the Global Volcanism Network. Ed. by R. Wunderman. Vol. 26. 4. Smithsonian Institution. DoI: 10.5479/si. GVP. BGVN200104-344100.

Gomez, C. (2014). "Digital photogrammetry and GISbased analysis of the bio-geomorphological evolution of Sakurajima Volcano, diachronic analysis from 1947 to 2006". Journal of Volcanology and Geothermal Research 280, pp. 1-13. DoI: $10.1016 / \mathrm{j}$. jvolgeores . 2014.04.015.

Gomez, C. and B. Kennedy (2018). "Capturing volcanic plumes in 3D with UAV-based photogrammetry at Yasur Volcano - Vanuatu". Journal of Volcanology and Geothermal Research 350, pp. 84-88. Dor: 10.1016/j . jvolgeores.2017.12.007.

Gomez, C. and H. Purdie (2016). "UAV- based Photogrammetry and Geocomputing for Hazards and Disaster Risk Monitoring - A Review". Geoenvironmental Disasters 3.1. DoI: 10.1186/s40677-016-๑๑60y.

Gouhier, M. and F. Donnadieu (2010). "The geometry of Strombolian explosions: insights from Doppler radar measurements". Geophysical Journal International 183.3, pp. 1376-1391. Dor: $10.1111 / \mathrm{j} .1365$ 246x.2010.04829.x.

- (2011). "Systematic retrieval of ejecta velocities and gas fluxes at Etna volcano using L-Band Doppler radar". Bulletin of Volcanology 73.9, pp. 1139-1145. Dor: $10.1007 / \mathrm{s} 00445-011-0500-1$.

Gurioli, L., A. Harris, L. Colò, J. Bernard, M. Favalli, M. Ripepe, and D. Andronico (2013). "Classification, landing distribution, and associated flight parameters for a bomb field emplaced during a single major explosion at Stromboli, Italy". Geology 41.5, pp. 559562. DoI: $10.1130 / \mathrm{g} 33967.1$.

Harris, A. and M. Ripepe (2007). "Temperature and dynamics of degassing at Stromboli". Journal of Geophysical Research 112.B3. DoI: 10.1029/2006jb004393.

Harris, A., M. Ripepe, and E. A. Hughes (2012). "Detailed analysis of particle launch velocities, size distributions and gas densities during normal explosions at Stromboli". Journal of Volcanology and Geothermal Research 231-232, pp. 109-131. DOI: 10 . 1016/j . jvolgeores. 2012.02.012.

Harvey, M., J. Rowland, and K. Luketina (2016). "Drone with thermal infrared camera provides high resolution georeferenced imagery of the Waikite geothermal area, New Zealand". Journal of Volcanology and Geothermal Research 325, pp. 61-69. Dor: 10.1016/j . jvolgeores.2016.06.014.

Houghton, B., D. Swanson, R. Carey, J. Rausch, and A. Sutton (2011). "Pigeonholing pyroclasts: In- sights from the 19 March 2008 explosive eruption of Kilauea volcano". Geology 39.3, pp. 263-266. DoI: 10.1130/g31509.1.

Iezzi, A. M., D. Fee, K. Kim, A. D. Jolly, and R. S. Matoza (2019). "Three-Dimensional Acoustic Multipole Waveform Inversion at Yasur Volcano, Vanuatu". Journal of Geophysical Research: Solid Earth 124.8, pp. 8679-8703. Dor: 10.1029/2018jb017073.

Jenkins, S., R. Spence, J. Fonseca, R. Solidum, and T. Wilson (2014). "Volcanic risk assessment: Quantifying physical vulnerability in the built environment". Journal of Volcanology and Geothermal Research 276, pp. 105-120. DoI: $10.1016 / \mathrm{j}$. jvolgeores . 2014.03 . 002.

Jolly, A. D., R. S. Matoza, D. Fee, B. M. Kennedy, A. M. Iezzi, R. H. Fitzgerald, A. C. Austin, and R. Johnson (2017). "Capturing the Acoustic Radiation Pattern of Strombolian Eruptions using Infrasound Sensors Aboard a Tethered Aerostat, Yasur Volcano, Vanuatu". Geophysical Research Letters 44.19, pp. 96729680. DOI: $10.1002 / 2017 \mathrm{gl} 074971$.

Jolly, G., H. Keys, J. Procter, and N. Deligne (2014). "Overview of the co-ordinated risk-based approach to science and management response and recovery for the 2012 eruptions of Tongariro volcano, New Zealand". Journal of Volcanology and Geothermal Research 286, pp. 184-207. Dor: $10.1016 / j$. jvolgeores . 2014.08 .028$.

Jordan, B. R. (2015). “A bird's-eye view of geology: The use of micro drones/UAVs in geologic fieldwork and education". GSA Today, pp. 50-52. Dor: 10.1130/ gsatg232gw. 1.

Kaneko, T., T. Koyama, A. Yasuda, M. Takeo, T. Yanagisawa, K. Kajiwara, and Y. Honda (2011). "Lowaltitude remote sensing of volcanoes using an unmanned autonomous helicopter: an example of aeromagnetic observation at Izu-Oshima volcano, Japan”. International Journal of Remote Sensing 32.5, pp. 1491-1504. DoI: 10.1080/01431160903559770.

Kaneko, T., F. Maeno, and S. Nakada (2016). "2014 Mount Ontake eruption: characteristics of the phreatic eruption as inferred from aerial observations". Earth, Planets and Space 68.1. DoI: 10.1186/ s40623-016-0452-y.

Kilgour, G., S. Gates, B. Kennedy, A. Farquhar, A. McSporran, and C. Asher (2019). "Phreatic eruption dynamics derived from deposit analysis: a case study from a small, phreatic eruption from Whakāri/White Island, New Zealand". Earth, Planets and Space 71.1. DOI: $10.1186 / s 40623-019-1008-8$.

Kilgour, G., V. Manville, F. D. Pasqua, A. Graettinger, K. Hodgson, and G. Jolly (2010). "The 25 September 2007 eruption of Mount Ruapehu, New Zealand: Directed ballistics, surtseyan jets, and ice-slurry lahars". Journal of Volcanology and Geothermal Research 191.1-2, pp. 1-14. DoI: 10.1016/j . jvolgeores . 2009. 10.015. 
Kremers, S., Y. Lavallée, J. Hanson, K.-U. Hess, M. O. Chevrel, J. Wassermann, and D. B. Dingwell (2012). "Shallow magma-mingling-driven Strombolian eruptions at Mt. Yasur volcano, Vanuatu". Geophysical Research Letters 39.21. DOI: 10 . 1029 / 2012 gl053312.

Kremers, S., J. Wassermann, K. Meier, C. Pelties, M. van Driel, J. Vasseur, and M. Hort (2013). "Inverting the source mechanism of Strombolian explosions at Mt. Yasur, Vanuatu, using a multi-parameter dataset". Journal of Volcanology and Geothermal Research 262, pp. 104-122. DoI: $10.1016 / \mathrm{j}$. jvolgeores. 2013.06 . $\odot \odot 7$.

Lorenz, V. (1970). "Some Aspects of the Eruption Mechanism of the Big Hole Maar, Central Oregon". Geological Society of America Bulletin 81.6, p. 1823. DoI: 10.1130/0016-7606(1970)81 [1823: saotem]2 . 0. co; 2.

Maeno, F., S. Nakada, M. Nagai, and T. Kozono (2013). "Ballistic ejecta and eruption condition of the vulcanian explosion of Shinmoedake volcano, Kyushu, Japan on 1 February, 2011". Earth, Planets and Space 65.6, pp. 609-621. DoI: 10.5047/eps. 2013.03.004.

Marchetti, E., M. Ripepe, D. D. Donne, R. Genco, A. Finizola, and E. Garaebiti (2013). "Blast waves from violent explosive activity at Yasur Volcano, Vanuatu”. Geophysical Research Letters 40.22, pp. 5838-5843. DOI: $10.1002 / 2013 \mathrm{gl} 057900$.

Mastin, L. G. (1991). "The roles of magma and groundwater in the phreatic eurptions at Inyo Craters, Long Valley Caldera, California". Bulletin of Volcanology 53.8, pp. 579-596. DoI: $10.1007 / \mathrm{bf0} 0493687$.

Matoza, R. S. et al. (2017). "Seismo-acoustic wavefield of strombolian explosions at Yasur volcano, Vanuatu, using a broadband seismo-acoustic network, infrasound arrays, and infrasonic sensors on tethered balloons". The Journal of the Acoustical Society of America 141.5, pp. 3566-3566. Dor: 10.1121/1.4987573.

McGetchin, T. R., M. Settle, and B. A. Chouet (1974). "Cinder cone growth modeled after Northeast Crater, Mount Etna, Sicily". Journal of Geophysical Research 79.23, pp. 3257-3272. DOI: 10 . $1029 /$ jb079i023p03257.

McGonigle, A. J. S., A. Aiuppa, G. Giudice, G. Tamburello, A. J. Hodson, and S. Gurrieri (2008). "Unmanned aerial vehicle measurements of volcanic carbon dioxide fluxes". Geophysical Research Letters 35.6. DOI: $10.1029 / 2007 \mathrm{gl} 1032508$.

Meier, K., M. Hort, J. Wassermann, and E. Garaebiti (2016). "Strombolian surface activity regimes at Yasur volcano, Vanuatu, as observed by Doppler radar, infrared camera and infrasound". Journal of Volcanology and Geothermal Research 322, pp. 184-195. Dor: 10.1016/j.jvolgeores.2015.07.038.

Merle, O., E. Brothelande, J.-F. Lénat, P. Bachèlery, and E. Garaébiti (2013). "A structural outline of the Yenkahe volcanic resurgent dome (Tanna Island, Vanuatu Arc, South Pacific)". Journal of Volcanology and Geothermal Research 268, pp. 64-72. Dor: 10 . 1016/j. jvolgeores. 2013.10.009.

Métrich, N., P. Allard, A. Aiuppa, P. Bani, A. Bertagnini, H. Shinohara, F. Parello, A. D. Muro, E. Garaebiti, O. Belhadj, and D. Massare (2011). "Magma and Volatile Supply to Post-collapse Volcanism and Block Resurgence in Siwi Caldera (Tanna Island, Vanuatu Arc)". Journal of Petrology 52.6, pp. 1077-1105. DOI: 10 . 1093/petrology/egro19.

Minakami, T. (1942). "On the distribution of volcanic ejecta (Part I.): The distributions of volcanic bombs ejected by the recent explosions of Asama". Bulletin of the Earthquake Research Institute, Tokyo Imperial University 20.1, pp. 65-92.

Minakami, T., S. Utibori, and S. Hiraga (1969). "The 1968 Eruption of Volcano Arenal, Costa Rica”. Bulletin of the Earthquake Research Institute, University of Tokyo 47.4, pp. 783-802.

Nabyl, A., J. Dorel, and M. Lardy (1997). "A comparative study of low-frequency seismic signals recorded at Stromboli volcano, Italy, and at Yasur volcano, Vanuatu". New Zealand Journal of Geology and Geophysics 40.4, pp. 549-558. DOI: $10.1080 / 00288306$. 1997.9514783.

Nairn, I. and S. Self (1978). "Explosive eruptions and pyroclastic avalanches from Ngauruhoe in February 1975". Journal of Volcanology and Geothermal Research 3.1-2, pp. 39-60. DoI: 10.1016/0377-0273(78)900033.

Nakano, T., I. Kamiya, M. Tobita, J. Iwahashi, and H. Nakajima (2014). "Landform monitoring in active volcano by UAV and SfM-MVS technique". ISPRS International Archives of the Photogrammetry, Remote Sensing and Spatial Information Sciences XL-8, pp. 7175. Dor: 10.5194/isprsarchives-xl-8-71-2014.

Novellis, V. D. and G. Luongo (2006). "Chapter 5 Ballistics shower during plinian scenario at Vesuvius". Vesuvius - Education, Security and Prosperity. Elsevier, pp. 265-285. DoI: 10.1016/s1871-644x(06) 80009-4.

Oppenheimer, C., P. Bani, J. Calkins, M. Burton, and G. Sawyer (2006). "Rapid FTIR sensing of volcanic gases released by Strombolian explosions at Yasur volcano, Vanuatu". Applied Physics B 85.2-3, pp. 453-460. Dor: 10.1007/s00340-006-2353-4.

Patterson, M., A. Mulligan, J. Douglas, J. Robinson, and J. Pallister (2005). "Volcano Surveillance by ACR Silver Fox”. Infotech@Aerospace. American Institute of Aeronautics and Astronautics. Dor: 10.2514/6.20056954.

Pichon, A. L. (2005). "Infrasound monitoring of volcanoes to probe high-altitude winds". Journal of Geophysical Research 110.D13. DOI: 10.1029/ $2004 \mathrm{jd} 005587$.

Pioli, L., E. Erlund, E. Johnson, K. Cashman, P. Wallace, M. Rosi, and H. D. Granados (2008). "Explosive dynamics of violent Strombolian eruptions: The eruption of Parıcutin Volcano 1943-1952 (Mexico)". 
Earth and Planetary Science Letters 271.1-4, pp. 359368. DoI: $10.1016 / \mathrm{j}$.epsl.2008.04.026.

Pistolesi, M., M. Rosi, L. Pioli, A. Renzulli, A. Bertagnini, and D. Andronico (2008). "The Paroxysmal Event and Its Deposits". The Stromboli Volcano: An Integrated Study of the 2002-2003 Eruption. American Geophysical Union, pp. 317-329. Dor: 10.1029/ $182 \mathrm{gm} 26$.

Pitchika, R. (2017). "Ballistic impact crater modelling using UAV and structure from motion technology: 2012 Te Maari volcanic eruptions, New Zealand". MA thesis. University of Canterbury.

Robertson, R., P. Cole, R. S. J. Sparks, C. Harford, A. M. Lejeune, W. J. McGuire, A. D. Miller, M. D. Murphy, G. Norton, N. F. Stevens, and S. R. Young (1998). "The explosive eruption of Soufriere Hills Volcano, Montserrat, West Indies, 17 September, 1996". Geophysical Research Letters 25.18, pp. 3429-3432. Dor: 10.1029/98g101442.

Rosi, M., A. Bertagnini, A. Harris, L. Pioli, M. Pistolesi, and M. Ripepe (2006). "A case history of paroxysmal explosion at Stromboli: Timing and dynamics of the April 5, 2003 event". Earth and Planetary Science Letters 243.3-4, pp. 594-606. Dor: 10.1016/j . epsl. 2006.01.035.

Salvatore, V., A. Silleni, D. Corneli, J. Taddeucci, D. M. Palladino, G. Sottili, D. Bernini, D. Andronico, and A. Cristaldi (2018). "Parameterizing multi-vent activity at Stromboli Volcano (Aeolian Islands, Italy)". Bulletin of Volcanology 80.7. Dor: 10.1007/s00445-0181239-8.

Self, S., J. Kienle, and J.-P. Huot (1980). "Ukinrek Maars, Alaska, II. Deposits and formation of the 1977 craters". Journal of Volcanology and Geothermal Research 7.1-2, pp. 39-65. DoI: 10.1016/0377-0273(80) 90019- 0 .

Shinohara, H. (2013). "Composition of volcanic gases emitted during repeating Vulcanian eruption stage of Shinmoedake, Kirishima volcano, Japan". Earth, Planets and Space 65.6, pp. 667-675. Dor: 10.5047/ eps.2012.11.001.

Spina, L., J. Taddeucci, A. Cannata, S. Gresta, L. Lodato, E. Privitera, P. Scarlato, M. Gaeta, D. Gaudin, and D. M. Palladino (2015). "Explosive volcanic activity at Mt. Yasur: A characterization of the acoustic events (9-12th July 2011)". Journal of Volcanology and Geothermal Research 302, p. 24. Dor: 10.1016/ j. jvolgeores.2015.06.005.

Steinberg, G. S. (1974). "On explosive caldera formation". Modern Geology 5, pp. 27-30.

- (1976). "On the determination of the energy and depth of volcanic explosions (paper dedicated to G. S. Gorshkov)". Bulletin Volcanologique 40.2, pp. 116120. DoI: $10.1007 / \mathrm{bf} 02599856$.

Steinberg, G. S. and V. Lorenz (1983). "External ballistic of volcanic explosions". Bulletin Volcanologique 46.4, pp. 333-348. Dor: 10.1007/bf02597769.
Stern, C. R. (2007). "Chilean volcanoes". The geology of Chile. Ed. by T. Moreno and W. Gibbons. Geological Society of London, pp. 147-178.

Swanson, D. A., S. P. Zolkos, and B. Haravitch (2012). "Ballistic blocks around Kilauea Caldera: Their vent locations and number of eruptions in the late 18th century". Journal of Volcanology and Geothermal Research 231-232, pp. 1-11. Dor: $10.1016 / \mathrm{j}$. jvolgeores.2012.04.008.

Taddeucci, J., M. A. Alatorre-Ibargüengoitia, O. CruzVázquez, E. D. Bello, P. Scarlato, and T. Ricci (2017). "In-flight dynamics of volcanic ballistic projectiles". Reviews of Geophysics 55.3, pp. 675-718. DOI: 10 . 1002/2017rg000564.

Taddeucci, J., M. A. Alatorre-Ibargüengoitia, D. M. Palladino, P. Scarlato, and C. Camaldo (2015). "High-speed imaging of Strombolian eruptions: Gaspyroclast dynamics in initial volcanic jets". Geophysical Research Letters 42.15, pp. 6253-6260. Dor: 10 . 1002/2015gl064874.

Taddeucci, J., P. Scarlato, A. Capponi, E. D. Bello, C. Cimarelli, D. M. Palladino, and U. Kueppers (2012). "High-speed imaging of Strombolian explosions: The ejection velocity of pyroclasts". Geophysical Research Letters 39.2. DoI: 10.1029/2011gl050404.

Thouret, J.-C., F. Lavigne, K. Kelfoun, and S. Bronto (2000). "Toward a revised hazard assessment at Merapi volcano, Central Java". Journal of Volcanology and Geothermal Research 100.1-4, pp. 479-502. Dor: 10 . 1016/s0377-0273(00)00152-9.

Tsunematsu, K., Y. Ishimine, T. Kaneko, M. Yoshimoto, T. Fujii, and K. Yamaoka (2016). "Estimation of ballistic block landing energy during 2014 Mount Ontake eruption". Earth, Planets and Space 68.1. Dor: 10.1186/s40623-016-0463-8.

Turner, N. R., R. L. Perroy, and K. Hon (2017). "Lava flow hazard prediction and monitoring with UAS: a case study from the 2014-2015 Pāhoa lava flow crisis, Hawai' $i$ '. Journal of Applied Volcanology 6.1. Dor: 10. 1186/s13617-017-0068-3.

Vanuatu Meteorology and Geohazards Department (2019a). Vanuatu Monthly Climate Summary July 2019. URL: https://www.vmgd.gov.vu/vmgd/images/ climate - media / docs / Vanuatu_Climate_ Summary / Vanuatu\%5C\%20Climate\%5C\%20Summary_July_2019. pdf (visited on 07/11/2020).

- (2019b). Yasur Visitor Fact Sheet. URL: https://www . vmgd. gov. vu/vmgd/index . php/geohazards/volcano/ volcano-info/resources (visited on 07/11/2020).

Waitt, R., L. Mastin, and T. Miller (1995). "Ballistic showers during crater peak eruptions of Mount Spurr volcano, summer 1992". The 1992 eruptions of Crater Peak vent, Mount Spurr Volcano, Alaska. Ed. by T. E. Keith. US Geological Survey. Dor: 10.3133/b2139.

Wardman, J., V. Sword-Daniels, C. Stewart, and T. Wilson (2012). Impact assessment of the May 2010 eruption of Pacaya volcano, Guatemala. University of Canterbury. Geological Sciences. 
Westoby, M., J. Brasington, N. Glasser, M. Hambrey, and J. Reynolds (2012). '“Structure-from-Motion' photogrammetry: A low-cost, effective tool for geoscience applications". Geomorphology 179, pp. 300314. DoI: $10.1016 / \mathrm{j}$. geomorph.2012.08.021.

Williams, G. T., B. Kennedy, T. Wilson, R. Fitzgerald, K. Tsunematsu, and A. Teissier (2017). "Buildings vs. ballistics: Quantifying the vulnerability of buildings to volcanic ballistic impacts using field studies and pneumatic cannon experiments". Journal of Volcanology and Geothermal Research 343, pp. 171-180. DoI: 10.1016/j . jvolgeores.2017.06.026.

Williams, G. T., B. M. Kennedy, D. Lallemant, T. M. Wilson, N. Allen, A. Scott, and S. F. Jenkins (2019).
"Tephra cushioning of ballistic impacts: Quantifying building vulnerability through pneumatic cannon experiments and multiple fragility curve fitting approaches". Journal of Volcanology and Geothermal Research 388, p. 106711. DoI: 10.1016/j . jvolgeores. 2019.106711.

Yamagishi, H. and C. Feebrey (1994). "Ballistic ejecta from the 1988-1989 andesitic Vulcanian eruptions of Tokachidake volcano, Japan: morphological features and genesis". Journal of Volcanology and Geothermal Research 59.4, pp. 269-278. DOI: 10 . 1016/0377$0273(94) 90082-5$. 